Published in final edited form as:

Gastroenterology. 2011 December ; 141(6): 1986-1999. doi:10.1053/j.gastro.2011.10.002.

\title{
Inflammasomes in Intestinal Inflammation and Cancer
}

\author{
Grace Y. Chen ${ }^{1}$ and Gabriel Núñez ${ }^{2}$ \\ ${ }^{1}$ Division of Hematology and Oncology, Department of Internal Medicine, and Comprehensive \\ Cancer Center, University of Michigan, Ann Arbor, MI 48109 \\ ${ }^{2}$ Department of Pathology, and Comprehensive Cancer Center, University of Michigan, MI 48109
}

\begin{abstract}
Inflammasomes are multi-protein complexes that mediate activation of caspase-1, which promotes secretion of the proinflammatory cytokines interleukin (IL)-1 $\beta$ and IL-18 and pyroptosis, a form of phagocyte cell death induced by bacterial pathogens. Members of the Nod-like receptor family (including Nlrp1, Nlrp3, and Nlrc4), the DNA sensor Aim2, the adaptor ASC, and pro-caspase-1 are important components of inflammasomes. Stimulation with specific microbial and endogenous molecules leads to inflammasome assembly and caspase-1 activation. Inflammasomes are believed to mediate host defense against microbial pathogens and tissue homeostasis within the intestine, and their dysregulation might contribute to inflammatory diseases and intestinal cancer. Improving our understanding of inflammasome signaling pathways could provide insights into pathogenesis of many gastrointestinal disorders and the development of therapeutics targets and approaches to treat diseases such as inflammatory bowel diseases and GI cancers.
\end{abstract}

\section{Keywords}

Caspase-1; Inflammasome; Interleukin-1 $\beta$; Innate Immunity; Immune; regulation; CRC; IBD; microbiota

\section{Introduction}

Within the gastrointestinal (GI), innate immune receptors function as an immediate defense mechanism against invasive pathogens. In 2004, Rakoff-Nahoum et al. discovered that pattern recognition receptors (PRRs), which sense commensal bacteria, maintain intestinal homeostasis and resistance to injury ${ }^{1}$. This was not surprising because PRRs signal through inflammatory pathways that include factors such as nuclear factor (NF)- $\mathrm{kB}$, mitogenactivated protein kinase (MAPK), and caspase-1. PRRs are not only involved in controlling infection and bacterial colonization, but also in regulating intestinal epithelial barrier function, epithelial repair, and immune homeostasis ${ }^{1-5}$. Therefore, in the GI tract, defects in PRR function could be involved in the pathogenesis of disorders such as infectious colitis, inflammatory bowel diseases, and cancer.

There are at least 4 major classes of PRRs that are involved in pathogen recognition. These are the Toll-like receptors (TLRs), the Nod-like receptors (NLRs), the RIG-I-like receptors (RLRs), and the C-type lectin receptors. Generally, these PRRs sense conserved structural motifs or pathogen-associated molecular patterns (PAMPs) in microbes, such as lipopolysaccharide or peptidoglycan, which are in the bacterial cell wall. PRRs are capable of sensing host-derived endogenous damage-associated molecular patterns (DAMPs), which 
are typically generated during cellular injury or tissue damage ${ }^{6}$. In contrast to the TLRs, which are located on the extracellular surface of cells and on endosomes, NLRs are located within the cytoplasm and recognize PAMPs and DAMPs that have gained access to the intracellular environment. NLRs are defined by a tripartite structure: first, an N-terminal caspase recruitment domain (CARD), pyrin domain (PYD), acidic transactivating domain, or baculovirus inhibitor repeat (BIR) that mediate downstream protein protein interactions; second, a central nucleotide-binding oligomerization (NOD) domain, which mediates selfoligomerization important during activation; and third, C-terminal leucine-rich repeats (LRR) that determines ligand specificity ${ }^{7}$.

The NLR family member Nod2 has been associated with risk for Crohn's disease. However, a subclass of NLRs that participate specifically in inflammasome signaling has been studied for its role in intestinal inflammation and homeostasis, because of its ability to promote production of the pro-inflammatory cytokines interleukin (IL)-1 $\beta$ and IL-18. We review the characteristics, function, and roles of inflammasomes in inflammation, homeostasis, host defense, and pathologies of the GI tract.

\section{Definition and Components}

The inflammasome is multi-protein platform that is characterized by its ability to activate pro-caspase-1, which in turn, proteolytically cleaves pro-IL-1 $\beta$ and pro-IL-18 into their mature active forms ${ }^{8}$. Inflammasomes are named by the PRR that regulates its activity and dictates the nature of the upstream activating stimulus. There are 4 known inflammasomes: the Nlrp1-, Nlrp3-, Nlrc4-, and Aim2-inflammasomes based on their dependence on caspase-1 activation for IL-1 $\beta$ and IL-18 production ${ }^{6}$. Nlrp1, Nlrp3, Nlrc4, and Aim2 are PRRs that are capable of sensing both PAMPs and also DAMPs in the case of Nlrp3. With the exception of Aim2, which is a member of the interferon-inducible HIN-200 protein family, the other known inflammasomes all contain a PRR that belong to the NLR family. As part of the NLR family, these specific members contain either an N-terminal PYD or CARD domain, which can interact with the PYD domain of the adaptor protein ASC and CARD domain of caspase-1 respectively. ASC similarly contains a CARD domain in addition to its PYD domain which can interact with the CARD domain of caspase-1 during activation. Nlrc4, which does not contain an N-terminal PYD domain as the others, contains instead an N-terminal CARD domain which can theoretically directly recruit caspase-1 through a CARD-CARD interaction. Based on genetic, biochemical and NMR studies, the prevailing model for inflammasome assembly and caspase- 1 activation is the following ${ }^{8-10}$ (Figure 1). Activation of the PRR by PAMPs/DAMPS results in oligomerization through the NOD domain of the PRR. Subsequently, through CARD-CARD and PYD-PYD proteinprotein interactions, a large macromolecular complex akin to the apoptosome involved in the activation of caspase- 9 via Apaf- 1 in apoptosis ${ }^{11}$, is assembled, which serves as a scaffold for procaspase-1 recruitment and self-cleavage into active caspase-1. Caspase- 1 activation then leads to the production of active IL-1 $\beta$, IL-18 and processsing of other substrates such as pro-caspase- $7^{12}$. In addition, caspase- 1 activation mediates pyroptosis, a specific form of early cell death induced by intracellular pathogens that promotes cellular lysis and the release of intracellular inflammatory contents to stimulate additional inflammatory signaling pathways ${ }^{13,14}$. Thus, cellular events that require IL-1 $\beta$ and IL-18 production or pyroptosis usually involve inflammasome activation; however, there are a few known exceptions where cleavage of pro-IL-1 $\beta$ and pro-IL-18 can occur independently of the inflammasome ${ }^{15,16}$.

\section{Inflammasome Activators}

Both microbial and non-microbial stimuli can induce the activation of inflammasomes. Importantly, activation of each NLR or Aim2 inflammasome is induced by specific 
microbial (Table I) or endogenous molecules. Although the molecular basis of the specificity is not well understood, the stimulus-specific activation of each inflammasome is largely determined by the fact that particular activating molecule(s) are sensed by individual NLRs or Aim2. Unlike Aim2 that directly binds cytosolic double-stranded DNA, there is no conclusive evidence as yet that NLRs involved in the inflammasome interact directly with activating microbial or endogenous molecules. Thus, it is possible that the recognition of upstream molecules by inflammasome NLRs is indirect and mediated through intermediate factors as it has been proposed for other mammalian NLR family members or their plant homologues ${ }^{17,18}$. We discuss below the specific stimuli and mechanisms that activate the inflammasomes that are more relevant to gastrointestinal inflammation including Nlrc4, Nlrp1, and Nlrp3.

\section{NLRC4}

Several Gram-negative bacteria, including Legionella pneumophila, Pseudomonas aeruginosa, and the enteric pathogens, Salmonella typhimurium and Shigella flexneri, induce caspase- 1 activation via the Nlrc4 inflammasome. The activation of the Nlrc4 inflammasome requires an intact type III secretion system (T3SS) for $S$. typhimurium, $S$. flexneri, and $P$. aeruginosa or type IV secretion system (T4SS) for $L$. pneumophila ${ }^{19-22}$. Upon infection, these secretion systems form pores in host cell membranes that mediate translocation of a wide array of virulence factors (effectors proteins) into the cell cytosol which is critical for pathogen colonization and induced pathology ${ }^{23}$. Mutant analyses of $S$. typhimurium, L. pneumophila and $P$. aeruginosa revealed that flagellin, a component of the flagellum apparatus that is required for bacterial motility, is critical for activation of caspase-1 via Nlrc $4^{19-21}$. Because cytosolic delivery or expression of flagellin is sufficient to trigger the activation of the Nlrc4-inflammasome, small amounts of flagellin leaked via the T3SS or T4SS into the host cytosol appears to be the signal for Nlrc4 activation during bacterial infection. Caspase-1 activation induced by flagellin is independent of TLR5, another PRR that senses this component of the flagellum ${ }^{19}$. Thus, flagellin is separately recognized by two different sensors; TLR5 senses extracellular flagellin whereas Nlrc4 recognizes flagellin in the cytosol. In addition to flagellin, there is evidence that PrgJ, a conserved inner rod component of the T3SS of Salmonella, can activate Nlrc4 ${ }^{24}$. Notably, Shigella does not express flagellin, but robustly activates caspase-1 via Nlrc ${ }^{24}$. Although the specific molecule produced by Shigella that activates Nlrc4 remains to be identified, it is possible that its conserved $\operatorname{Prg} \mathrm{J}$ homologue is involved because expression of a functional T3SS is required for caspase- 1 activation.

Recent evidence indicate that the activation of Nlrc4 requires the presence of Naip5, another NLR family member. Naip5 appears to sense the C-terminal portion of flagellin from $L$. pneumophila and is required for the activation of the Nlrc4 inflammasome in response to this bacterium ${ }^{25}$. It was proposed that Naip5 physically associates with Nlrc4 to form an inflammasome complex in response to L. pneumophila. In contrast, caspase-1 activation induced by $S$. typhimurium and $P$. aeruginosa infection, which is also triggered by cytosolic flagellin, is largely Naip5-independent ${ }^{25}$. Because L. pneumophila expressing Salmonella flagellin activates Nlrc4 in a Naip5-dependent manner ${ }^{26}$, the differential requirement of Naip5 is not due to differences in the flagellin molecule between the two bacterial species. Recently, two groups have shown that flagellin directly associates with Naip5 whereas the related Naip2 binds TTSS rod proteins ${ }^{27,28}$. These results suggest that activation of the Nlrc4 inflammasome is mediated indirectly through the interaction of specific microbial molecules with distinct Naip proteins. 
NLRP1

The human NLRP1 inflammasome was the first caspase-1-activating protein complex to be identified ${ }^{8}$. Furthermore, the NLRP1 was the only inflammasome reconstituted in vitro with purified components, which revealed that NLRP1 oligomerizes with caspase-1 in the presence of muramyl dipeptide (MDP) ${ }^{9}$. Using this in vitro system, it was suggested that caspase- 1 is activated via a two-step mechanism whereby microbial MDP induces a conformational change in NLRP1, which, in turn, allows it to bind nucleotide and oligomerize, leading to caspase- 1 activation $^{9}$. However, direct evidence that MDP binds NLRP1 is lacking, and therefore, the mechanism that triggers NLRP1 oligomerization remains unclear. Notably, the adaptor molecule ASC enhanced, but was not required for NLRP1-mediated caspase-1 activation in vitro ${ }^{9}$, which is consistent with the observation that ASC is not essential for the activation of caspase-1 mediated by Nlrp1b in mouse macrophages ${ }^{29}$. Thus, the adaptor ASC is essential for the activation of caspase- 1 in the great majority, but not all, inflammasomes. Unlike humans that possess a single NLRP1 gene, three NIrp1 paralogs, namely NIrp1a, $-b$ and $-c$, are present in the mouse genome. The Nlrp1b-inflammasome is activated by lethal toxin (LT), a bipartite toxin secreted by Bacillus anthracis that is composed of Protective Antigen (PA), a pore-forming subunit that delivers Lethal factor, a metalloprotease, into the cytosol of infected cells ${ }^{29}$. An important role for the Nlrp1b-inflammasome in host defense is suggested by the observation that mice harboring the Nlrp1b "susceptible" allele are more sensitive to LT $^{30,31}$. Recent evidence indicate that caspase-1 activation in response to $B$. anthracis infection is beneficial to the host $^{32,33}$. However, the mechanism by which Lethal factor, triggers Nlrp1b-inflammasome activation remains poorly understood.

\section{NLRP3}

Unlike Nlrc4 that is activated primarily by cytosolic flagellin, a large array of microbial and non-microbial stimuli have been reported to activate the Nlrp3 inflammasome in macrophages. These include several TLR agonists and the Nod2 agonist MDP in the presence of extracellular ATP ${ }^{34-36}$. In addition, Nlrp3 is activated by certain bacterial toxins and particulate matter including urate crystals, silica, asbestos, $\beta$-amyloid, and aluminum hydroxide in phagocytes pre-stimulated with microbial ligands such as lipopolysaccharide $(\text { LPS })^{37-40}$. The ability of multiple PAMPs to activate the Nlrp3-inflammasome is puzzling because most of these molecules including TLR ligands are structurally unrelated. Recent findings suggest that most, if not all, TLR agonists as well as MDP, do not act as direct Nlrp3 activators ${ }^{41,42}$. Instead, these microbial stimuli promote inflammasome activation indirectly through the induction of Nlrp3 via NF- $\mathrm{KB}$ signaling whereas ATP provides the direct signal for inflammasome activation ${ }^{41,42}$ (Figure 2A). Similarly, bacterial toxins and particulate matter activate Nlrp3, but they still require pre-stimulation with TLR ligands which induce Nlrp3 expression ${ }^{37-40}$ (Figure 2B). Consistently, TNF- $a$ and IL-1 that activate $\mathrm{NF}-\mathrm{\kappa B}$ are as effective as TLR agonists in promoting caspase-1 activation in response to ATP or silica ${ }^{40,42}$

\section{Mechanism of NLRP3 activation}

Activation of the Nlrp3 inflammasome requires 2 signals. The first signal is provided by microbial molecules such as TLR ligands or by certain cytokines that induce induction of Nlrp3 via NF- $\mathrm{kB}$ (Figure 2A). The second signal directly triggers caspase-1 activation, and can be mediated by several stimuli including extracellular ATP, particulate matter, and certain bacterial toxins (Figure 2B). It is likely that these different pathways culminate in a common step that leads to Nlrp3 activation. However, the identification of a unifying mechanism of Nlrp3 activation remains elusive. Extracellular ATP acting through the ATPgated $\mathrm{P} 2 \mathrm{X} 7$ receptor (P2X7R) and bacterial toxins that activate Nlrp3 in a P2X7Rindependent manner induce potent $\mathrm{K}^{+}$efflux, a signal that appears to be required for Nlrp3 
inflammasome activation ${ }^{43}$. Although Nlrp3-inflammasome activation is effectively blocked by high concentrations of extracellular $\mathrm{K}^{+}$, it is not clear whether $\mathrm{K}^{+}$efflux is induced by all stimuli that activate Nlrp3 and is sufficient to trigger inflammasome activation. Earlier studies suggested that P2X7R activates Nlrp3 via the formation of a large pore mediated by pannexin- $1^{44,45}$. However, recent work clearly showed that Nlrp3 activation proceeds independently of pannexin- $1^{46}$. Lysosomal membrane damage induced by silica and other particles has been suggested to play an important role in Nlrp3 activation through the activation of lysosomal proteases and specifically cathepsin $\mathrm{B}^{38}$. However, caspase- 1 activation-induced by ATP is cathepsin B-independent ${ }^{38}$, suggesting that cathepsin B activation is not the unifying link to Nlrp3 activation. The generation of reactive oxygen species (ROS) was proposed to be the common step in Nlrp3 activation largely based on the observation that caspase- 1 activation is blocked by ROS inhibitors $39,47,48$. However, recent studies have challenged the role of ROS in Nlrp3 activation. For example, recent evidence indicate that ROS inhibitors do not block the activation of the Nlrp3 inflammasome, but prevent the upregulation of Nlrp3 and pro-IL-1 $\beta$, thus acting on the priming of cells $\mathrm{s}^{49}$. Furthermore, the evidence suggesting a critical role of thioredoxin-interacting protein (TXNIP), an inhibitor of the antioxidant thioredoxin, in Nlrp3 activation was not reproduced ${ }^{50}$. Thus, a critical role for ROS in inducing Nlrp3 inflammasome activation is doubtful. Clearly, further work is needed to understand the mechanism of the Nlrp3 inflammasome.

\section{NLRP6 as a Possible Regulator of the Inflammasome}

Nlrp6 is an as yet poorly characterized NLR that contains an N-terminal PYD domain, a central NOD domain, and C-terminal LRRs. Although the nature of the signal which activates Nlrp6 remains unknown, early studies based on the overexpression of NLRP6 suggested its role as an inflammasome participant ${ }^{51}$. Specifically, co-expression of NLRP6 with ASC resulted in cooperative production of IL- $1 \beta$ in COS-7L cells that was caspase-1 dependent and required the presence of the PYD domain ${ }^{51}$. Furthermore, immunofluorescence studies demonstrated colocalization of NLRP6 with ASC in a characteristic speckled pattern within the cytoplasm ${ }^{51}$. Presumably, the PYN domain of NLRP6 may directly interact with the PYD domain of ASC to enable caspase-1 activation, although a direct interaction with ASC or caspase-1 has never been demonstrated. More recently, Nlrp6-deficient mice were shown to have impaired steady-state levels of IL-18 production within the serum and in colon explant cultures compared with wildtype mice ${ }^{52}$, consistent with a role in inflammasome signaling although we have not observed differences in basal IL-18 levels between Nlrp6 ${ }^{-1-}$ and wildtype colon tissue homogenates ${ }^{53}$.

Until recently, a function for Nlrp6 was unknown. Expression analysis of Nlrp6 on an mRNA level showed that it was highly expressed in the intestine and significantly less so in hematopoietic cells ${ }^{51,53-55}$. However, in hematopoietic cells, Nlrp6 was demonstrated to be expressed differentially with greater expression levels detected in granulocytes and lymphocytes as compared with macrophages and dendritic cells ${ }^{51}$. Others have reported high expression levels within myofibroblasts, which have important roles in intestinal epithelial repair ${ }^{55,56}$, although whether Nlrp6 functions within this group of cells is unknown. In the past year, several reports have confirmed a role for Nlrp6 in promoting intestinal homeostasis (see below). Whether Nlrp6 truly functions as part of an inflammasome however remains to be determined in vivo and will require a better understanding of its upstream signals and whether the production of IL-1 $\beta$ and IL-18 via Nlrp6 is ASC and caspase-1 dependent. 


\section{Host Defense}

Acute infectious diarrhea is a major cause of morbidity and mortality worldwide especially in developing countries and in children. Pathogens such as Staphylococcus aureus, enteropathogenic Escherichia coli, and Vibrio cholera are capable of producing toxins that cause diarrhea and others such as Salmonella, Campylobacter, Shigella and rotavirus are invasive and can cause severe intestinal inflammation. Inflammasomes play an important role in host defense against enteropathogenic bacteria. For example, there is evidence that activation of the Nlrc4 inflammasome functions as a host defense strategy against pathogenic infections. In the case of $S$. typhymurium and $S$. flexneri, Nlrc4-dependent activation of caspase- 1 is accompanied by the secretion of IL- $1 \beta$ and the induction of pyroptosis ${ }^{19,57}$. Surprisingly, while both Nlrc4 and the adaptor molecule ASC are required for caspase- 1 activation and IL- $1 \beta$ secretion, Nlrc4, but not ASC, is critical for the induction of pyroptosis ${ }^{21,22}$. There is evidence that the inflammasome is important in host defense against Salmonella infection in vivo. For example, caspase-1-null mice are more susceptible to oral infection which is associated with increased bacterial loads in the spleen and mesenteric lymph nodes ${ }^{58,59}$. Caspase-1 plays a role in the systemic phase of the infection because caspase-1 deficient mice were more susceptible than wild-type mice when challenged with Salmonella intraperitoneally ${ }^{59}$. Furthermore, IL-18 was suggested as the critical cytokine responsible for host defense against Salmonella ${ }^{59}$. However, Nlrc4deficient mice were as susceptible as wild-type mice ${ }^{58}$. The latter results can be explained by the observation that Salmonella down-regulates the expression of flagellin during the systemic phase of the infection ${ }^{60}$. Consistently, Nlrc4 plays an important role in host defense against the bacterium when expression of flagellin in Salmonella is enforced during the systemic phase of the infection ${ }^{61}$. Salmonella encodes two T3SS, SPI-1 promotes invasion of intestinal epithelial cells while SP1-2 promotes replication in macrophages 62 . Recently, it was reported that in SPI-1 deficient Salmonella strains Nlrc4 acts redundantly with Nlrp3 to induce the activation of caspase- $1^{63}$. The mechanism by which SPI-2 activates the Nlrp3 inflammasome, however, remains unknown.

Infection of macrophages by several bacterial pathogens including Salmonella triggers pyroptosis that relies on caspase- 1 activation ${ }^{64}$. Surprisingly, while both Nlrc4 and the adaptor ASC are required for caspase- 1 activation and IL- $1 \beta$ secretion, Nlrc4, but not ASC, is critical for the induction of pyroptosis ${ }^{21,22,65}$. Although the precise mechanism remains poorly understood, there is evidence that IL- $1 \beta$ secretion and pyroptosis are mediated by distinct caspase- 1 signaling pathways that can be separated by the involvement of ASC ${ }^{65}$. In the intestinal phase, Salmonella expresses SPI-1 and flagellin, leading to activation of caspase-1 via Nlrc4 whereas in the systemic phase, Salmonella expresses neither SPI-1 nor flagellin. However the forced expression of flagellin during the systemic phase of the infection reveals an important role for Nlrc4-dependent pyroptosis in promoting bacterial clearance. Specifically Nlrc4-induced pyroptosis promoted the release of intracellular bacteria from phagocytic cells leading to uptake and killing of the pathogen by neutrophils ${ }^{61}$. This process occurs independently of IL-1 $\beta$ and IL-18 possibly explaining why the adaptor ASC is not required to regulate the susceptibility to Salmonella infection ${ }^{58,61}$.

Several pathogenic microorganisms including certain viruses, fungi and bacteria induce the activation of the Nlrp3-inflammasome. Among the pathogenic bacteria, $S$. aureus, $S$. pyogenes, and $V$. cholera activate caspase-1 via Nlrp3 ${ }^{66-68}$. Specifically, pore-forming or membrane-damaging toxins produced by pathogenic bacteria are important in inducing activation of the Nlrp3-inflammasome ${ }^{66-68}$. Unlike extracellular ATP, Nlrp3 activation induced by bacterial infection is independent of the P2X7R ${ }^{66-68}$. Nlrp3 also regulates IL-1 $\beta$ production in response to several viruses, such as influenza A, fungi, such as Candida 
albicans and parasites, including Plasmodium ${ }^{69,70}$. However, whether Nlrp3 regulates host defense against viruses or helminths that specifically cause pathology in the intestine remains to be determined.

\section{Tissue Repair and GI Homeostasis}

\section{IL-1 $\beta$ vs IL-18}

Inflammatory bowel disease is a debilitating condition that afflicts approximately 1.4 million people in the United States and 2.2 million in Europe ${ }^{71}$. IBD encompasses two different diseases, ulcerative colitis (UC) and Crohn's disase (CD) in which the intestine becomes chronically inflamed leading to the common clinical presentation of abdominal pain, bloody diarrhea and weight loss. UC and CD are distinguished by clinical and endoscopic criteria as well as histology. In UC, inflammation is restricted to the mucosal layer of the colon typically in the rectum and can extend continuously to involve other areas of the colon, whereas in $\mathrm{CD}$, inflammation is transmural and can occur in a discontiguous fashion ('skip lesions') that involve any part of the gastrointestinal tract, most commonly in the distal ileum. Because of the transmural nature of involvement, complications such as bowel strictures and fistula formation can occur that is rarely associated with ulcerative colitis. The pathogenesis of IBD remains unclear, but studies suggest both an environmental and genetic contribution ${ }^{72,73}$. Generally, the prevailing model for the development of IBD involves an aberrant immune response to commensal bacteria and/or an imbalance in the structure of the gut microbiota ${ }^{74}$.

An interest in the role of inflammasomes in the pathogenesis of IBD arose from observations that polymorphisms in genes encoding IL-18 and the IL-18 accessory protein were associated with increased susceptibility to Crohn's disease ${ }^{75,76}$. In addition, polymorphisms in specific inflammasome components, particularly Nlrp3, which resulted in impaired IL- $1 \beta$ production by LPS-stimulated monocytes was associated with increased susceptibility to $\mathrm{CD}^{77}$ although this observation was not reproducible in different populations ${ }^{78}$. Nonetheless, these initial genetic linkage studies suggest a role for inflammasome signaling and IL- $1 \beta$ and IL-18 production in IBD development.

There are several mouse models of IBD that have been used to understand mechanisms of IBD development, but the one that has been used most frequently to investigate the role of the inflammasome has been the chemically-induced colitis by dextran sulfate sodium $(\mathrm{DSS})^{73}$. DSS causes direct epithelial injury causing epithelial cell death and increased intestinal permeability, which results in mucosal ulceration and erosion, infiltration of inflammatory cells, and upregulation of proinflammatory cytokines ${ }^{79,80,81}$. Lesions typically affect only the mucosal layer primarily in the colon and rectum as in ulcerative colitis, but can develop discontinuously unlike UC. Criticism against the DSS model that is more representative of acute epithelial injury has been the lack of T cell-dependence, an important component of IBD, as DSS-induced colitis can still occur in T-cell deficient animals, although $\mathrm{T}$ cells can contribute to its severity ${ }^{82-85}$. Nonetheless, the DSS model has been useful in identifying critical factors important in the intestinal epithelial repair and barrier function as well as innate immune responses involved in the development and control of enteric inflammation.

Since IBD is typically associated with upregulation of proinflammatory cytokine induction including IL- $1 \beta$ and IL- $18^{86,87}$, one can reasonably hypothesize that downregulation of these proinflammatory cytokines would be associated with decreased disease severity. Indeed, it was initially demonstrated that caspase-1-deficient Balb/c mice were less susceptible to DSS-induced colitis with improved clinical and histologic scores compared to wildtype mice ${ }^{88}$. Consistently, IL-18 overexpressing transgenic mice were associated with 
increased colitis ${ }^{89}$ and chemical inhibition of IL-18 or caspase-1 was associated with amelioration of disease $\mathrm{e}^{90,91}$.

However, more recent studies have demonstrated a negative regulatory role of inflammasome signaling in the development of colitis. Specifically, both ASC- and caspase-1-deficient B6 mice had increased susceptibility to DSS with impaired epithelial proliferation and restitution, increased intestinal permeability, and greater translocation of commensal bacteria into the colonic mucosa and mesenteric lymph nodes ${ }^{92}$. Although caspase- 1 and ASC deficiency was associated with reductions in both IL- $1 \beta$ and IL-18 production, the mechanism behind the increased severity of inflammation in caspase-1deficient mice was linked to an impairment in IL-18 production, as administration of recombinant IL-18 was sufficient to rescue caspase-1 deficient B6 mice ${ }^{92}$. It was further suggested that the source of IL-18 was in the intestinal epithelial cell based on in vitro cultures of intestinal cells enriched in epithelial versus lamina propria cells from DSStreated mice ${ }^{92}$. The impairment in IL-18 production in caspase-1 deficient mice during DSSinduced colitis and the ability to rescue with administration of IL-18 was also reproduced by a separate group giving credence to the model that caspase-1dependent IL-18 production, presumably by the intestinal epithelium, is important for epithelial repair and regeneration during DSS-induced colitis ${ }^{93}$ (Figure 3). However, the source of IL-18 may not solely be from the epithelium because there is evidence that IL-18 is produced by both epithelial and lamina propia cells in IBD ${ }^{94}$.

IL-18 has traditionally been considered pro-inflammatory with importance in inducing Th1 responses, specifically IFN- $\gamma$, and therefore the precise mechanism by which IL-18 promotes early tissue repair remains unclear ${ }^{95}$. However, the IL-18 receptor signals through the adaptor protein MyD88, which has been implicated in intestinal epithelial repair through interactions with prostaglanding and Cox-2 signaling pathways ${ }^{1,96,97}$. IL-18 has also been shown to be important in other models of wound repair such as in the $\operatorname{skin}^{98}$. Thus, the extent of IL-18 production may dictate the level of inflammation and repair such that any dysregulation in IL-18 production can disrupt this fine balance within the intestine. It remains intriguing why there are discrepant results in the phenotype of caspase- 1 deficient mice between the current studies and earlier studies, and it may have been due in part to differences in mouse genetic background (Balb/c versus B6, respectively). However, it has also been recently reported that caspase-1 deficient B6 mice treated with DSS did not demonstrate any difference in inflammation than wildtype mice ${ }^{99}$. Although differences in the length and concentration of DSS treatment (2\% DSS for 7 days versus 3\% for 5 days) may be one explanation, a more likely and concerning possibility is the difference in the gut microbiota between different facilities.

Role of NLRP3 in GI Homeostasis-Which PRR component of the inflammasome is important for caspase- 1 activation and protection against chemically-induced injury and intestinal homeostasis? Given the possible genetic association between Nlrp3 and IBD ${ }^{77}$, much attention has been given to the role of Nlrp3. Three different groups have demonstrated that Nlrp3-deficient mice had increased susceptibility to DSS-induced colitis with increased mortality and weight loss ${ }^{93,100,101}$. Nlrp3-deficient mice had increased mortality, increased rectal bleed and colonic inflammation histologically. The increased colonic inflammation in DSS-treated Nlrp3-deficient mice was associated with increased intestinal permeability and translocation of bacteria to the liver and mesenteric lymph nodes. Similar to what was observed in caspase-1 deficient mice, Nlrp3-deficient mice had an impairment in epithelial proliferation, suggesting a defect in epithelial repair as the mechanism to the increased severity of symptoms ${ }^{93}$ (Figure 3). However, whether Nlrp3deficient mice had impaired IL-18 production or whether the administration of recombinant IL-18 is capable of rescuing Nlrp3-deficient mice has not yet been demonstrated. 
Nonetheless, bone marrow chimera experiments suggested that Nlrp3 function in radioresistant, non-hematopoietic cells is important for protection against DSS-induced colitis, consistent with the model of intestinal homeostasis maintained by intestinal epithelial IL-18 production although a role for other non-hematopoietic cells has not been entirely excluded ${ }^{93}$ (Figure 3 ). Therefore, IL-18 production to promote intestinal homeostasis may be mediated by the Nlrp3 inflammasome. Another possible mechanism for the protective role of Nlrp3 was suggested by a study by Hirota et al. who demonstrated an impairment in $\beta$ defensin production in Nlrp3-deficient mice that was associated with a microbiota composition distinct from that in wildtype mice ${ }^{101}$. Thus, an interesting possibility yet to be fully explored is that Nlrp3-deficiency results in defective antimicrobial mechanisms, which, in turn, causes bacterial dysbiosis that leads to increased susceptibility to DSS-induced colitis.

However, despite the convincing data that Nlrp3 functions to protect against DSS-induced colitis, there are at least two groups that do not show a negative regulatory effect of Nlrp3 on colitis. Bauer et al., found that their Nlrp3-null mice had less severe colitis when treated with DSS, which was related to decreased IL-1 $\beta$ secretion of DSS-treated Nlrp3-deficient macrophages in vitro ${ }^{102}$. Similarly pharmacological inhibition of caspase-1 with pralnacasan also resulted in decreased severity of colitis ${ }^{90}$. A second group has also shown an attenuated colitis pattern in Nlrp3-deficient mice ${ }^{52}$. It is difficult to attribute these differences entirely to differences in protocol. Rather, baseline differences in the microbiota may more likely explain dissimilar phenotypes.

NLRP6 and Regulation of the GI Microbiota-DSS-induced colitis has not been studies with respect to other known inflammasomes such as Nlrc4, Aim2, or Nlrp1. However, as discussed above, Nlrp6 likely participates in inflammasome signaling based on in vitro studies and is also highly expressed in the intestine. Recent reports now confirm Nlrp6 to be another important factor in the regulation of intestinal homeostasis ${ }^{52,53,55}$. We have recently reported that Nlrp6-deficient mice have increased susceptibility to DSSinduced colitis which was also demonstrated by two other groups ${ }^{52,53,55}$. Flavell and colleagues provide a possible mechanism for Nlpr6-mediated protection (Figure 4). Through high throughput culture-independent 16S RNA bacterial gene sequencing, they demonstrated that the gut microbiota of Nlrp6 mice was distinct from that in wildtype mice, and furthermore, the microbiota associated with Nrlp6 mice were colitogenic that was transferrable to wildtype mice with co-housing 52 . This phenomenon was specific to Nlrp6 and did not occur with mice deficient in other inflammasome components such as Nlrc4 and Aim2. Specifically, they showed that there was greater colonization of the bacterial genus Prevotollaceae in Nlrp6-deficient mice ${ }^{52}$. Treatment of Nlrp6-deficient mice with antibiotics resulted in a reduction of these bacteria, improvement in colitis, and reduced transferability of colitis to wildtype mice after cohousing ${ }^{52}$. Interestingly, the authors demonstrate that the gut microbiome of Nlrp6-deficient mice was associated with increased CCL5 production. While CCL5-deficient mice developed DSS-induced colitis that was not significantly different from wildtype mice, CCL5-deficient mice developed colitis that was less severe than wildtype mice after cohousing with Nlrp6-deficient mice despite an equivalent transfer of Prevotellaceae. The authors therefore suggest that the aberrant microbiota of Nlrp6deficient mice results in greater CCL5 production that predisposes to greater inflammation upon chemically-induced epithelial damage by DSS as Nlrp6-deficient mice do not develop spontaneous colitis ${ }^{52}$ (Figure 4). In addition, Nlrp6 had impaired IL-18 production specifically within the non-hematopoietic compartment, or epithelium ${ }^{52}$, which can further reduce the ability of Nlrp6-deficient mice to recover from DSS-induced epithelial injury ${ }^{52}$. This would be consistent with the proposed model for caspase- 1 activation and IL-18 production in intestinal homeostasis; however, whether the administration of IL-18 is capable of rescuing Nlrp6-deficient mice and furthermore, whether Nlrp6 function 
specifically in the epithelium by generating bone marrow chimeras was not investigated and remains to be determined. It is also worth mentioning that it remains unclear whether Nlrp6 truly regulates the gut microbiota as bacterial sequencing was performed on mice that were not littermates, and therefore differences in microbiota may merely have been due to differences in ancestry. Although antibiotic treatment was associated with decreases in Prevotellaceae, effects on other bacterial groups that contribute to susceptibility to colitis also cannot be excluded. Regardless, these studies have identified potentially colitogenic bacteria that can be targeted for therapeutic purposes. Monocolonization experiments with germfree mice would be helpful to definitively determine the true colitogenic potential of the Prevotellaceae and TM7 species.

\section{Tumorigenesis}

\section{IL-18 in Colitis-Associated Tumorigenesis}

Colorectal cancer is the third most common cancer and is also the third most common cause of cancer-related deaths. There are two major risk factors for the development of colorectal cancer, that is, a genetic predisposition, and inflammatory bowel disease. Even in sporadic colon cancers, $80 \%$ is associated with a genetic mutations in the tumor suppressor APC. APC participates in the Wnt signaling pathway which is upregulated in colon stem cells and activated under conditions of cellular proliferation. Mice that harbor a mutation in the Apc gene (ApcMin mice), develop spontaneous small intestinal and colon tumors, although the majority of tumors are in the small intestine. These mice are often used to model spontaneous colon carcinogenesis ${ }^{103}$. Innate immune signaling and commensal bacteria have been shown to be important in this mouse model as ApcMin mice that are also deficient in the MyD88 have decreased tumor potential, and germ-free ApcMin mice have a slight decrease in small intestinal tumorigenesis ${ }^{104,105}$. There, however, does not appear to be a role for inflammasomes in spontaneous tumorigenesis in this model as ApcMin mice that were crossed to either IL-1 receptor (IL-1R) or caspase-1 deficient mice had no difference in polyp formation compared to ApcMin mice ${ }^{106}$. Furthermore, the administration of the IL-1R antagonist anakinra did not affect the extent of tumorigenesis ${ }^{106}$.

On the other hand, in the presence of inflammation, inflammasomes can have a critical role in colon tumorigenesis. Colitis-associated colon cancer (CAC) is a major complication of IBD, and directly correlates with the extent and duration of colitis. The link between chronic inflammation and carcinogenesis can be explained by the production of DNA-damaging oxygen radical species, proinflammatory mediators that promote cellular survival, enhance proliferation and angiogensis and tissue remodeling, resulting in a microenvironment conducive to tumorigenesis ${ }^{107}$. A popularly used mouse model for CAC is the AOM/DSS model in which the experimental carcinogen azoxymethane is use to introduce genomic mutations by methylation followed by repeated rounds of DSS to induce a chronic pattern of colitis $^{108}$. After three rounds of DSS, mice develop grossly visible adenomas, and if mice are sacrificed at later time points, the proportion of adenocarcinomas increases, suggesting that this model recapitulates events involved in the progression from premalignant adenomas to adenocarcinomas in humans ${ }^{109}$. However, this model has been criticized as not fully encapsulating important features of CAC, such as the frequency of APC mutations which occurs early in the AOM/DSS model, but late and less commonly in $\mathrm{CAC}^{110}$, and the predominance of adenomatous polyps typical of the AOM/DSS model as opposed to flat dysplastic lesions more commonly seen in IBD ${ }^{111}$. Regardless, this model has been useful in identifying factors and signaling pathways important in modulating inflammation and subsequent carcinogenesis. 
Given the tight association between inflammation and colorectal cancer, it is not surprising that inflammasomes which function to protect the intestine from excessive inflammation after chemically-induced injury would have a role in determining susceptibility to CAC (Figure 5). In the AOM/DSS model, although IL-1R-deficient mice develop a similar number of tumors as wildtype mice, IL-18 and IL-18R-deficient mice both have increased number of tumors, suggesting a role for inflammasome signaling in tumor suppression in the context of chronic inflammation ${ }^{112}$. Mice deficient in MyD88, which is downstream of IL-18 signaling, mice also had increased tumors in the AOM/DSS model associated with depressed levels of various DNA repair factors in addition to enhanced expression of mitogenic and angiogenic genes. ${ }^{112}$ Thus, it has been suggested that altered DNA repair mechanisms may contribute to increased tumorigenesis in mice deficient in MyD88, which is downstream of IL-18 receptor signaling.

NLRP3 in CAC-Upstream of IL-18, Nlrp3 has also been reported to negatively regulate colitis-associated tumorigenesis ${ }^{100,113}$. However, the mechanism remains unclear. Kanneganti and colleagues demonstrate that caspase-1-deficient mice have more tumors similar to Nlrp3-deficient mice that was associated with decreased IL-18 production and STAT1 activation ${ }^{113}$. Administration of IL-18 restored wildtype levels of STAT1 phosphorylation and therefore, the authors posit that IL-18 signaling is important for IFN $\gamma$ induction and immune surveillance ${ }^{113}$. However, whether normalization of STAT1 signaling with IL-18 administration resulted in less tumors was not demonstrated. Ting and colleagues also demonstrated increased susceptibility of Nlrp3-deficient and consistently ASC-deficient mice to colitis-associated tumors associated with a defect in IL-18 production during the induction of inflammation in the AOM/DSS model ${ }^{100}$. Interestingly, in bone marrow chimera experiments, they show that Nlrp3 is important in the hematopoietic compartment rather than in the epithelial compartment, suggesting a role for the inflammasome in tumor suppression that is independent of IL-18 production by the intestinal epithelium. It is also possible that in contrast to inflammation, tumorigenesis requires inflammasome function in the hematopoietic cell compartment as opposed to the epithelial compartment.

\section{NLRP6 suppresses intestinal tumorigenesis in addition to inflammation-}

Similar to what was observed for Nlrp3, we have also demonstrated an important role for Nlrp6, particularly in the hematopoietic compartment, in protecting against the development of colitis associated tumors ${ }^{53}$. This result is intriguing given the fact that Nlrp6 is more highly expressed in the epithelium and to a much lesser extent in hematopoietic cells, although it is possible that similar to Nlrp3, Nlrp6 expression is inducible upon activation ${ }^{53}$. The increased tumorigenesis was associated with increased inflammatory responses, but defective IL-18 production within the colon after AOM/DSS treatment ${ }^{53}$. How this relates to increased tumor potential remains to be delineated especially given the predominance of IL-18 production by the intestinal epithelium rather than by colon lamina propria or bone marrow-derived cells ${ }^{53}$. Using gene expression analysis by microarray profiling of tumors in Nlrp6 and WT mice, Chamaillard and colleagues observed differences in the signaling molecules of the pathways important in epithelial proliferation and transformation, such as the Notch and Wnt pathways, and therefore suggest that dysregulation of these pathways in Nlrp6-deficient mice are contributing factors to tumorigenesis 55 . Clearly, additional experiments investigating the relationship between IL-18 production, Nlrp6 function in the hematopoietic cell, and other carcinogenic signaling pathways potentially regulated by Nlrp6 need to be done.

NLRC4 Regulates Tumorigenesis Independently of Inflammation-Nlrc4 has also been demonstrated to be capable of suppressing tumors, although this remains 
controversial as 2 different groups have shown inconsistent results with one study demonstrating no role for Nlrc $4^{100}$ in colitis-associated tumor development and another showing a negative regulatory role for Nlrc $4{ }^{99}$. Specifically, Flavell and colleagues demonstrate that Nlrc4-deficient mice developed increased tumors in the AOM/DSS model, which was unrelated to inflammation, as the severity of colitis in these mice was no different from that observed in wildtype mice ${ }^{99}$. Instead, Nlrc4 deficiency was associated with increased epithelial proliferation and decreased apoptosis in advanced tumors ${ }^{99}$. Although the mechanism behind this phenomenon is unclear, the authors demonstrate in bone marrow chimeric experiments that Nlrc4 function in the non-hematopoietic cell compartment is important for tumor suppression and suggest that Nlrc4 signaling within the epithelium is important for regulating apoptosis and proliferation within tumors ${ }^{99,114}$. However, caspase-1 function was required in both hematopoietic and epithelial compartments ${ }^{99}$, perhaps due to the influence of other upstream inflammasome components that function in the hematopoietic compartment for tumor suppression (e.g., Nlrp3 or Nlrp6). Interestingly, Ting and colleagues found no difference in tumor potential between Nlrc4 and wildtype mice using the AOM/DSS model ${ }^{100}$, suggesting again that differences in the gut microbiota in different facilities may influence the outcome of Nlrc4 deficiency.

\section{Conclusion}

Inflammasomes, as PRRs, are important in the defense against pathogenic organisms that can invade the GI tract. However, an extended role for inflammasomes in maintaining the integrity of the intestinal epithelium and promoting repair has clearly emerged, placing inflammasomes as important players in the pathogenesis of inflammatory bowel disease and cancer. Recent studies have also implicated the inflammasome in regulating the GI microbiome, which in turn, can affect host susceptibility to diseases beyond the GI tract, including obesity and diabetes. As the repertoire of microbial and host-derived signals sensed by inflammasomes become better understood, strategies to modulate inflammasome activity may be extremely useful in the development of therapeutics for a variety of diseases, not just limited to the GI tract.

\section{Acknowledgments}

We dedicate this article to the memory of Jürg Tschopp who passed away suddenly on March 22, 2011. We apologize to our colleagues whose work was not cited or was cited through others' review articles because of space limitations. We would like to thank Luigi Franchi for his critique of the manuscript. Work in the authors' laboratories is supported by National Institutes of Health grants CA133185, P30 CA46592-22S3 and American Cancer Society Research Scholar Grant (to G.Y.C.) and National Institutes of Health Grants DK61707, AR051790, AI06331, AR059688, and DK091191 (to G.N.)

\section{Abbreviations used in this paper}

$\begin{array}{ll}\text { AOM } & \text { azoxymethane } \\ \text { ASC } & \text { adaptor apoptosis associated speck-like protein } \\ \text { CAC } & \text { colitis-associated colon cancer } \\ \text { CARD } & \text { caspase recruitment domain } \\ \text { CD } & \text { Crohn's disease } \\ \text { DSS } & \text { dextran sulfate sodium } \\ \text { DAMPs } & \text { damage-associated molecular patterns } \\ \text { IBD } & \text { inflammatory bowel disease }\end{array}$




$\begin{array}{ll}\text { IL-1 } \beta & \text { interleukin-1 } \beta \\ \text { IL-18 } & \text { interleukin-18 } \\ \text { LPS } & \text { lipopolysaccharide } \\ \text { LRRs } & \text { leucine-rich repeats } \\ \text { MDP } & \text { muramyl dipeptide } \\ \text { NLRs } & \text { Nod-like receptors } \\ \text { NOD } & \text { nucleotide-binding oligomerization domain } \\ \text { PAMPs } & \text { pathogen-associated molecular patterns } \\ \text { P2X7R } & \text { purinergic P2X7 receptor } \\ \text { PRRs } & \text { pattern-recognition receptors } \\ \text { PYD } & \text { pyrin domain } \\ \text { RLRs } & \text { RiG-I-like receptors } \\ \text { T3SS } & \text { type III secretion system } \\ \text { T4SS } & \text { type IV secretion system } \\ \text { TLRs } & \text { Toll-like receptors } \\ \text { UC } & \text { ulcerative colitis }\end{array}$

\section{References}

1. Rakoff-Nahoum S, Paglino J, Eslami-Varzaneh F, Edberg S, Medzhitov R. Recognition of commensal microflora by toll-like receptors is required for intestinal homeostasis. Cell. 2004; 118:229-41. [PubMed: 15260992]

2. Chen GY, Shaw MH, Redondo G, Nunez G. The innate immune receptor Nod1 protects the intestine from inflammation-induced tumorigenesis. Cancer Res. 2008; 68:10060-7. [PubMed: 19074871]

3. Bouskra D, Brezillon C, Berard M, Werts C, Varona R, Boneca IG, Eberl G. Lymphoid tissue genesis induced by commensals through NOD1 regulates intestinal homeostasis. Nature. 2008; 456:507-10. [PubMed: 18987631]

4. Fukata M, Chen A, Vamadevan AS, Cohen J, Breglio K, Krishnareddy S, Hsu D, Xu R, Harpaz N, Dannenberg AJ, Subbaramaiah K, Cooper HS, Itzkowitz SH, Abreu MT. Toll-like receptor-4 promotes the development of colitis-associated colorectal tumors. Gastroenterology. 2007; 133:1869-81. [PubMed: 18054559]

5. Saleh M, Trinchieri G. Innate immune mechanisms of colitis and colitis-associated colorectal cancer. Nat Rev Immunol. 2011; 11:9-20. [PubMed: 21151034]

6. Chen GY, Nunez G. Sterile inflammation: sensing and reacting to damage. Nat Rev Immunol. 2010; 10:826-37. [PubMed: 21088683]

7. Chen G, Shaw MH, Kim YG, Nunez G. NOD-like receptors: role in innate immunity and inflammatory disease. Annu Rev Pathol. 2009; 4:365-98. [PubMed: 18928408]

8. Martinon F, Burns K, Tschopp J. The inflammasome: a molecular platform triggering activation of inflammatory caspases and processing of proIL-beta. Mol Cell. 2002; 10:417-26. [PubMed: 12191486]

9. Faustin B, Lartigue L, Bruey JM, Luciano F, Sergienko E, Bailly-Maitre B, Volkmann N, Hanein D, Rouiller I, Reed JC. Reconstituted NALP1 inflammasome reveals two-step mechanism of caspase-1 activation. Mol Cell. 2007; 25:713-24. [PubMed: 17349957]

10. de Alba E. Structure and interdomain dynamics of apoptosis-associated speck-like protein containing a CARD (ASC). J Biol Chem. 2009; 284:32932-41. [PubMed: 19759015] 
11. Bratton SB, Salvesen GS. Regulation of the Apaf-1-caspase-9 apoptosome. J Cell Sci. 2010; 123:3209-14. [PubMed: 20844150]

12. Lamkanfi M, Kanneganti TD, Van Damme P, Vanden Berghe T, Vanoverberghe I, Vandekerckhove J, Vandenabeele P, Gevaert K, Nunez G. Targeted peptidecentric proteomics reveals caspase-7 as a substrate of the caspase-1 inflammasomes. Mol Cell Proteomics. 2008; 7:2350-63. [PubMed: 18667412]

13. Fernandes-Alnemri T, Wu J, Yu JW, Datta P, Miller B, Jankowski W, Rosenberg S, Zhang J, Alnemri ES. The pyroptosome: a supramolecular assembly of ASC dimers mediating inflammatory cell death via caspase-1 activation. Cell Death Differ. 2007; 14:1590-604. [PubMed: 17599095]

14. Fink SL, Cookson BT. Pyroptosis and host cell death responses during Salmonella infection. Cell Microbiol. 2007; 9:2562-70. [PubMed: 17714514]

15. Mayer-Barber KD, Barber DL, Shenderov K, White SD, Wilson MS, Cheever A, Kugler D, Hieny S, Caspar P, Nunez G, Schlueter D, Flavell RA, Sutterwala FS, Sher A. Caspase-1 independent IL-1beta production is critical for host resistance to mycobacterium tuberculosis and does not require TLR signaling in vivo. J Immunol. 2010; 184:3326-30. [PubMed: 20200276]

16. van de Veerdonk FL, Netea MG, Dinarello CA, Joosten LA. Inflammasome activation and IL-1beta and IL-18 processing during infection. Trends Immunol. 2011; 32:110-6. [PubMed: 21333600]

17. DeYoung BJ, Innes RW. Plant NBS-LRR proteins in pathogen sensing and host defense. Nat Immunol. 2006; 7:1243-9. [PubMed: 17110940]

18. Franchi L, Warner N, Viani K, Nunez G. Function of Nod-like receptors in microbial recognition and host defense. Immunol Rev. 2009; 227:106-28. [PubMed: 19120480]

19. Franchi L, Amer A, Body-Malapel M, Kanneganti TD, Ozoren N, Jagirdar R, Inohara N, Vandenabeele P, Bertin J, Coyle A, Grant EP, Nunez G. Cytosolic flagellin requires Ipaf for activation of caspase-1 and interleukin 1beta in salmonella-infected macrophages. Nat Immunol. 2006; 7:576-82. [PubMed: 16648852]

20. Amer A, Franchi L, Kanneganti TD, Body-Malapel M, Ozoren N, Brady G, Meshinchi S, Jagirdar R, Gewirtz A, Akira S, Nunez G. Regulation of Legionella phagosome maturation and infection through flagellin and host Ipaf. J Biol Chem. 2006; 281:35217-23. [PubMed: 16984919]

21. Franchi L, Stoolman J, Kanneganti TD, Verma A, Ramphal R, Nunez G. Critical role for Ipaf in Pseudomonas aeruginosa-induced caspase-1 activation. Eur J Immunol. 2007; 37:3030-9. [PubMed: 17935074]

22. Suzuki T, Franchi L, Toma C, Ashida H, Ogawa M, Yoshikawa Y, Mimuro H, Inohara N, Sasakawa C, Nunez G. Differential regulation of caspase-1 activation, pyroptosis, and autophagy via Ipaf and ASC in Shigella-infected macrophages. PLoS Pathog. 2007; 3:e111. [PubMed: 17696608]

23. Galan JE, Wolf-Watz H. Protein delivery into eukaryotic cells by type III secretion machines. Nature. 2006; 444:567-73. [PubMed: 17136086]

24. Miao EA, Mao DP, Yudkovsky N, Bonneau R, Lorang CG, Warren SE, Leaf IA, Aderem A. Innate immune detection of the type III secretion apparatus through the NLRC4 inflammasome. Proc Natl Acad Sci U S A. 2010; 107:3076-80. [PubMed: 20133635]

25. Lightfield KL, Persson J, Brubaker SW, Witte CE, von Moltke J, Dunipace EA, Henry T, Sun YH, Cado D, Dietrich WF, Monack DM, Tsolis RM, Vance RE. Critical function for Naip5 in inflammasome activation by a conserved carboxy-terminal domain of flagellin. Nat Immunol. 2008; 9:1171-8. [PubMed: 18724372]

26. Lightfield KL, Persson J, Trinidad NJ, Brubaker SW, Kofoed EM, Sauer JD, Dunipace EA, Warren SE, Miao EA, Vance RE. Differential requirements for NAIP5 in activation of the NLRC4 inflammasome. Infect Immun. 2011; 79:1606-14. [PubMed: 21282416]

27. Zhao Y, Yang J, Shi J, Gong YN, Lu Q, Xu H, Liu L, Shao F. The NLRC4 inflammasome receptors for bacterial flagellin and type III secretion apparatus. Nature. 2011; 477:596-600. [PubMed: 21918512]

28. Kofoed EM, Vance RE. Innate immune recognition of bacterial ligands by NAIPs determines inflammasome specificity. Nature. 2011; 477:592-5. [PubMed: 21874021] 
29. Nour AM, Yeung YG, Santambrogio L, Boyden ED, Stanley ER, Brojatsch J. Anthrax lethal toxin triggers the formation of a membrane-associated inflammasome complex in murine macrophages. Infect Immun. 2009; 77:1262-71. [PubMed: 19124602]

30. Boyden ED, Dietrich WF. Nalp1b controls mouse macrophage susceptibility to anthrax lethal toxin. Nat Genet. 2006; 38:240-4. [PubMed: 16429160]

31. Kang TJ, Basu S, Zhang L, Thomas KE, Vogel SN, Baillie L, Cross AS. Bacillus anthracis spores and lethal toxin induce IL-1beta via functionally distinct signaling pathways. Eur J Immunol. 2008; 38:1574-84. [PubMed: 18493980]

32. Terra JK, Cote CK, France B, Jenkins AL, Bozue JA, Welkos SL, LeVine SM, Bradley KA. Cutting edge: resistance to Bacillus anthracis infection mediated by a lethal toxin sensitive allele of Nalp1b/Nlrp1b. J Immunol. 2010; 184:17-20. [PubMed: 19949100]

33. Moayeri M, Crown D, Newman ZL, Okugawa S, Eckhaus M, Cataisson C, Liu S, Sastalla I, Leppla SH. Inflammasome sensor Nlrp1b-dependent resistance to anthrax is mediated by caspase-1, IL-1 signaling and neutrophil recruitment. PLoS Pathog. 2010; 6:e1001222. [PubMed: 21170303]

34. Mariathasan S, Weiss DS, Newton K, McBride J, O'Rourke K, Roose-Girma M, Lee WP, Weinrauch Y, Monack DM, Dixit VM. Cryopyrin activates the inflammasome in response to toxins and ATP. Nature. 2006; 440:228-32. [PubMed: 16407890]

35. Sutterwala FS, Ogura Y, Szczepanik M, Lara-Tejero M, Lichtenberger GS, Grant EP, Bertin J, Coyle AJ, Galan JE, Askenase PW, Flavell RA. Critical role for NALP3/CIAS1/Cryopyrin in innate and adaptive immunity through its regulation of caspase-1. Immunity. 2006; 24:317-27. [PubMed: 16546100]

36. Franchi L, Kanneganti TD, Dubyak GR, Nunez G. Differential requirement of P2X7 receptor and intracellular $\mathrm{K}+$ for caspase-1 activation induced by intracellular and extracellular bacteria. J Biol Chem. 2007; 282:18810-8. [PubMed: 17491021]

37. Martinon F, Petrilli V, Mayor A, Tardivel A, Tschopp J. Gout-associated uric acid crystals activate the NALP3 inflammasome. Nature. 2006; 440:237-41. [PubMed: 16407889]

38. Hornung V, Bauernfeind F, Halle A, Samstad EO, Kono H, Rock KL, Fitzgerald KA, Latz E. Silica crystals and aluminum salts activate the NALP3 inflammasome through phagosomal destabilization. Nat Immunol. 2008; 9:847-56. [PubMed: 18604214]

39. Dostert C, Petrilli V, Van Bruggen R, Steele C, Mossman BT, Tschopp J. Innate immune activation through Nalp3 inflammasome sensing of asbestos and silica. Science. 2008; 320:674-7. [PubMed: 18403674]

40. Franchi L, Eigenbrod T, Munoz-Planillo R, Nunez G. The inflammasome: a caspase-1-activation platform that regulates immune responses and disease pathogenesis. Nat Immunol. 2009; 10:2417. [PubMed: 19221555]

41. Bauernfeind FG, Horvath G, Stutz A, Alnemri ES, MacDonald K, Speert D, Fernandes-Alnemri T, Wu J, Monks BG, Fitzgerald KA, Hornung V, Latz E. Cutting edge: NF-kappaB activating pattern recognition and cytokine receptors license NLRP3 inflammasome activation by regulating NLRP3 expression. J Immunol. 2009; 183:787-91. [PubMed: 19570822]

42. Franchi L, Eigenbrod T, Nunez G. Cutting edge: TNF-alpha mediates sensitization to ATP and silica via the NLRP3 inflammasome in the absence of microbial stimulation. J Immunol. 2009; 183:792-6. [PubMed: 19542372]

43. Kahlenberg JM, Dubyak GR. Mechanisms of caspase-1 activation by P2X7 receptor-mediated K+ release. Am J Physiol Cell Physiol. 2004; 286:C1100-8. [PubMed: 15075209]

44. Pelegrin P, Surprenant A. Pannexin-1 mediates large pore formation and interleukin-1beta release by the ATP-gated P2X7 receptor. EMBO J. 2006; 25:5071-82. [PubMed: 17036048]

45. Kanneganti TD, Lamkanfi M, Kim YG, Chen G, Park JH, Franchi L, Vandenabeele P, Nunez G. Pannexin-1-mediated recognition of bacterial molecules activates the cryopyrin inflammasome independent of Toll-like receptor signaling. Immunity. 2007; 26:433-43. [PubMed: 17433728]

46. Qu Y, Misaghi S, Newton K, Gilmour LL, Louie S, Cupp JE, Dubyak GR, Hackos D, Dixit VM. Pannexin-1 is required for ATP release during apoptosis but not for inflammasome activation. J Immunol. 2011; 186:6553-61. [PubMed: 21508259] 
47. Zhou R, Tardivel A, Thorens B, Choi I, Tschopp J. Thioredoxin-interacting protein links oxidative stress to inflammasome activation. Nat Immunol. 2010; 11:136-40. [PubMed: 20023662]

48. Zhou R, Yazdi AS, Menu P, Tschopp J. A role for mitochondria in NLRP3 inflammasome activation. Nature. 2011; 469:221-5. [PubMed: 21124315]

49. Bauernfeind F, Bartok E, Rieger A, Franchi L, Nunez G, Hornung V. Cutting Edge: Reactive Oxygen Species Inhibitors Block Priming, but Not Activation, of the NLRP3 Inflammasome. J Immunol. 2011; 187:613-7. [PubMed: 21677136]

50. Masters SL, Dunne A, Subramanian SL, Hull RL, Tannahill GM, Sharp FA, Becker C, Franchi L, Yoshihara E, Chen Z, Mullooly N, Mielke LA, Harris J, Coll RC, Mills KH, Mok KH, Newsholme P, Nunez G, Yodoi J, Kahn SE, Lavelle EC, O'Neill LA. Activation of the NLRP3 inflammasome by islet amyloid polypeptide provides a mechanism for enhanced IL-1beta in type 2 diabetes. Nat Immunol. 2010; 11:897-904. [PubMed: 20835230]

51. Grenier JM, Wang L, Manji GA, Huang WJ, Al-Garawi A, Kelly R, Carlson A, Merriam S, Lora JM, Briskin M, DiStefano PS, Bertin J. Functional screening of five PYPAF family members identifies PYPAF5 as a novel regulator of NF-kappaB and caspase-1. FEBS Lett. 2002; 530:73-8. [PubMed: 12387869]

52. Elinav E, Strowig T, Kau AL, Henao-Mejia J, Thaiss CA, Booth CJ, Peaper DR, Bertin J, Eisenbarth SC, Gordon JI, Flavell RA. NLRP6 inflammasome regulates colonic microbial ecology and risk for colitis. Cell. 2011; 145:745-57. [PubMed: 21565393]

53. Chen GY, Liu M, Wang F, Bertin J, Nunez G. A functional role for nlrp6 in intestinal inflammation and tumorigenesis. J Immunol. 2011; 186:7187-94. [PubMed: 21543645]

54. Lech M, Avila-Ferrufino A, Skuginna V, Susanti HE, Anders HJ. Quantitative expression of RIGlike helicase, NOD-like receptor and inflammasome-related mRNAs in humans and mice. Int Immunol. 2010; 22:717-28. [PubMed: 20584763]

55. Normand S, Delanoye-Crespin A, Bressenot A, Huot L, Grandjean T, Peyrin-Biroulet L, Lemoine Y, Hot D, Chamaillard M. Nod-like receptor pyrin domain-containing protein 6 (NLRP6) controls epithelial self-renewal and colorectal carcinogenesis upon injury. Proc Natl Acad Sci U S A. 2011; 108:9601-6. [PubMed: 21593405]

56. Andoh A, Bamba S, Brittan M, Fujiyama Y, Wright NA. Role of intestinal subepithelial myofibroblasts in inflammation and regenerative response in the gut. Pharmacol Ther. 2007; 114:94-106. [PubMed: 17328956]

57. Miao EA, Alpuche-Aranda CM, Dors M, Clark AE, Bader MW, Miller SI, Aderem A. Cytoplasmic flagellin activates caspase-1 and secretion of interleukin 1beta via Ipaf. Nat Immunol. 2006; 7:569-75. [PubMed: 16648853]

58. Lara-Tejero M, Sutterwala FS, Ogura Y, Grant EP, Bertin J, Coyle AJ, Flavell RA, Galan JE. Role of the caspase-1 inflammasome in Salmonella typhimurium pathogenesis. J Exp Med. 2006; 203:1407-12. [PubMed: 16717117]

59. Raupach B, Peuschel SK, Monack DM, Zychlinsky A. Caspase-1-mediated activation of interleukin-1beta (IL-1beta) and IL-18 contributes to innate immune defenses against Salmonella enterica serovar Typhimurium infection. Infect Immun. 2006; 74:4922-6. [PubMed: 16861683]

60. Alaniz RC, Cummings LA, Bergman MA, Rassoulian-Barrett SL, Cookson BT. Salmonella typhimurium coordinately regulates FliC location and reduces dendritic cell activation and antigen presentation to CD4+ T cells. J Immunol. 2006; 177:3983-93. [PubMed: 16951361]

61. Miao EA, Leaf IA, Treuting PM, Mao DP, Dors M, Sarkar A, Warren SE, Wewers MD, Aderem A. Caspase-1-induced pyroptosis is an innate immune effector mechanism against intracellular bacteria. Nat Immunol. 2010; 11:1136-42. [PubMed: 21057511]

62. Hueffer K, Galan JE. Salmonella-induced macrophage death: multiple mechanisms, different outcomes. Cell Microbiol. 2004; 6:1019-25. [PubMed: 15469431]

63. Broz P, Newton K, Lamkanfi M, Mariathasan S, Dixit VM, Monack DM. Redundant roles for inflammasome receptors NLRP3 and NLRC4 in host defense against Salmonella. J Exp Med. 2010; 207:1745-55. [PubMed: 20603313]

64. Lamkanfi M, Dixit VM. Manipulation of host cell death pathways during microbial infections. Cell Host Microbe. 2010; 8:44-54. [PubMed: 20638641] 
65. Broz P, von Moltke J, Jones JW, Vance RE, Monack DM. Differential requirement for Caspase-1 autoproteolysis in pathogen-induced cell death and cytokine processing. Cell Host Microbe. 2010; 8:471-83. [PubMed: 21147462]

66. Munoz-Planillo R, Franchi L, Miller LS, Nunez G. A critical role for hemolysins and bacterial lipoproteins in Staphylococcus aureus-induced activation of the Nlrp3 inflammasome. J Immunol. 2009; 183:3942-8. [PubMed: 19717510]

67. Harder J, Franchi L, Munoz-Planillo R, Park JH, Reimer T, Nunez G. Activation of the Nlrp3 inflammasome by Streptococcus pyogenes requires streptolysin O and NF-kappa B activation but proceeds independently of TLR signaling and P2X7 receptor. J Immunol. 2009; 183:5823-9. [PubMed: 19812205]

68. Toma C, Higa N, Koizumi Y, Nakasone N, Ogura Y, McCoy AJ, Franchi L, Uematsu S, Sagara J, Taniguchi S, Tsutsui H, Akira S, Tschopp J, Nunez G, Suzuki T. Pathogenic Vibrio activate NLRP3 inflammasome via cytotoxins and TLR/nucleotide-binding oligomerization domainmediated NF-kappa B signaling. J Immunol. 2010; 184:5287-97. [PubMed: 20348425]

69. Gross O, Poeck H, Bscheider M, Dostert C, Hannesschlager N, Endres S, Hartmann G, Tardivel A, Schweighoffer E, Tybulewicz V, Mocsai A, Tschopp J, Ruland J. Syk kinase signalling couples to the Nlrp3 inflammasome for anti-fungal host defence. Nature. 2009; 459:433-6. [PubMed: 19339971]

70. Reimer T, Shaw MH, Franchi L, Coban C, Ishii KJ, Akira S, Horii T, Rodriguez A, Nunez G. Experimental cerebral malaria progresses independently of the Nlrp3 inflammasome. Eur J Immunol. 2010; 40:764-9. [PubMed: 19950187]

71. Loftus EV Jr. Clinical epidemiology of inflammatory bowel disease: Incidence, prevalence, and environmental influences. Gastroenterology. 2004; 126:1504-17. [PubMed: 15168363]

72. Khor B, Gardet A, Xavier RJ. Genetics and pathogenesis of inflammatory bowel disease. Nature. 2011; 474:307-17. [PubMed: 21677747]

73. Strober W, Fuss IJ, Blumberg RS. The immunology of mucosal models of inflammation. Annu Rev Immunol. 2002; 20:495-549. [PubMed: 11861611]

74. Strober W, Fuss I, Mannon P. The fundamental basis of inflammatory bowel disease. J Clin Invest. 2007; 117:514-21. [PubMed: 17332878]

75. Tamura K, Fukuda Y, Sashio H, Takeda N, Bamba H, Kosaka T, Fukui S, Sawada K, Satomi M, Yamada T, Yamamura T, Yamamoto Y, Furuyama J, Okamura H, Shimoyama T. IL18 polymorphism is associated with an increased risk of Crohn's disease. J Gastroenterol. 2002; 37 (Suppl 14):111-6. [PubMed: 12572878]

76. Zhernakova A, Festen EM, Franke L, Trynka G, van Diemen CC, Monsuur AJ, Bevova M, Nijmeijer RM, van't Slot R, Heijmans R, Boezen HM, van Heel DA, van Bodegraven AA, Stokkers PC, Wijmenga C, Crusius JB, Weersma RK. Genetic analysis of innate immunity in Crohn's disease and ulcerative colitis identifies two susceptibility loci harboring CARD9 and IL18RAP. Am J Hum Genet. 2008; 82:1202-10. [PubMed: 18439550]

77. Villani AC, Lemire M, Fortin G, Louis E, Silverberg MS, Collette C, Baba N, Libioulle C, Belaiche J, Bitton A, Gaudet D, Cohen A, Langelier D, Fortin PR, Wither JE, Sarfati M, Rutgeerts P, Rioux JD, Vermeire S, Hudson TJ, Franchimont D. Common variants in the NLRP3 region contribute to Crohn's disease susceptibility. Nat Genet. 2009; 41:71-6. [PubMed: 19098911]

78. Lewis GJ, Massey DC, Zhang H, Bredin F, Tremelling M, Lee JC, Berzuini C, Parkes M. Genetic association between NLRP3 variants and Crohn's disease does not replicate in a large UK panel. Inflamm Bowel Dis. 2011; 17:1387-91. [PubMed: 21560198]

79. Cooper HS, Murthy SN, Shah RS, Sedergran DJ. Clinicopathologic study of dextran sulfate sodium experimental murine colitis. Lab Invest. 1993; 69:238-49. [PubMed: 8350599]

80. Okayasu I, Hatakeyama S, Yamada M, Ohkusa T, Inagaki Y, Nakaya R. A novel method in the induction of reliable experimental acute and chronic ulcerative colitis in mice. Gastroenterology. 1990; 98:694-702. [PubMed: 1688816]

81. Ni J, Chen SF, Hollander D. Effects of dextran sulphate sodium on intestinal epithelial cells and intestinal lymphocytes. Gut. 1996; 39:234-41. [PubMed: 8991862]

82. Axelsson LG, Landstrom E, Goldschmidt TJ, Gronberg A, Bylund-Fellenius AC. Dextran sulfate sodium (DSS) induced experimental colitis in immunodeficient mice: effects in CD4(+) -cell 
depleted, athymic and NK-cell depleted SCID mice. Inflamm Res. 1996; 45:181-91. [PubMed: 8741008]

83. Shintani N, Nakajima T, Okamoto T, Kondo T, Nakamura N, Mayumi T. Involvement of CD4+ T cells in the development of dextran sulfate sodium-induced experimental colitis and suppressive effect of IgG on their action. Gen Pharmacol. 1998; 31:477-81. [PubMed: 9703223]

84. Chen Y, Chou K, Fuchs E, Havran WL, Boismenu R. Protection of the intestinal mucosa by intraepithelial gamma delta T cells. Proc Natl Acad Sci U S A. 2002; 99:14338-43. [PubMed: 12376619]

85. Kim TW, Seo JN, Suh YH, Park HJ, Kim JH, Kim JY, Oh KI. Involvement of lymphocytes in dextran sulfate sodium-induced experimental colitis. World J Gastroenterol. 2006; 12:302-5. [PubMed: 16482634]

86. Street ME, de'Angelis G, Camacho-Hubner C, Giovannelli G, Ziveri MA, Bacchini PL, Bernasconi S, Sansebastiano G, Savage MO. Relationships between serum IGF-1, IGFBP-2, interleukin-1 beta and interleukin-6 in inflammatory bowel disease. Horm Res. 2004; 61:159-64. [PubMed: 14691340]

87. Li J, Moran T, Swanson E, Julian C, Harris J, Bonen DK, Hedl M, Nicolae DL, Abraham C, Cho JH. Regulation of IL-8 and IL-1beta expression in Crohn's disease associated NOD2/CARD15 mutations. Hum Mol Genet. 2004; 13:1715-25. [PubMed: 15198989]

88. Siegmund B, Lehr HA, Fantuzzi G, Dinarello CA. IL-1 beta -converting enzyme (caspase-1) in intestinal inflammation. Proc Natl Acad Sci U S A. 2001; 98:13249-54. [PubMed: 11606779]

89. Ishikura T, Kanai T, Uraushihara K, liyama R, Makita S, Totsuka T, Yamazaki M, Sawada T, Nakamura T, Miyata T, Kitahora T, Hibi T, Hoshino T, Watanabe M. Interleukin-18 overproduction exacerbates the development of colitis with markedly infiltrated macrophages in interleukin-18 transgenic mice. J Gastroenterol Hepatol. 2003; 18:960-9. [PubMed: 12859727]

90. Bauer C, Loher F, Dauer M, Mayer C, Lehr HA, Schonharting M, Hallwachs R, Endres S, Eigler A. The ICE inhibitor pralnacasan prevents DSS-induced colitis in C57BL/6 mice and suppresses IP-10 mRNA but not TNF-alpha mRNA expression. Dig Dis Sci. 2007; 52:1642-52. [PubMed: 17393315]

91. Siegmund B, Fantuzzi G, Rieder F, Gamboni-Robertson F, Lehr HA, Hartmann G, Dinarello CA, Endres S, Eigler A. Neutralization of interleukin-18 reduces severity in murine colitis and intestinal IFN-gamma and TNF-alpha production. Am J Physiol Regul Integr Comp Physiol. 2001; 281:R1264-73. [PubMed: 11557635]

92. Dupaul-Chicoine J, Yeretssian G, Doiron K, Bergstrom KS, McIntire CR, LeBlanc PM, Meunier C, Turbide C, Gros P, Beauchemin N, Vallance BA, Saleh M. Control of intestinal homeostasis, colitis, and colitis-associated colorectal cancer by the inflammatory caspases. Immunity. 2010; 32:367-78. [PubMed: 20226691]

93. Zaki MH, Boyd KL, Vogel P, Kastan MB, Lamkanfi M, Kanneganti TD. The NLRP3 inflammasome protects against loss of epithelial integrity and mortality during experimental colitis. Immunity. 2010; 32:379-91. [PubMed: 20303296]

94. Pizarro TT, Michie MH, Bentz M, Woraratanadharm J, Smith MF Jr, Foley E, Moskaluk CA, Bickston SJ, Cominelli F. IL-18, a novel immunoregulatory cytokine, is up-regulated in Crohn's disease: expression and localization in intestinal mucosal cells. J Immunol. 1999; 162:6829-35. [PubMed: 10352304]

95. Nakanishi K, Yoshimoto T, Tsutsui H, Okamura H. Interleukin-18 regulates both Th1 and Th2 responses. Annu Rev Immunol. 2001; 19:423-74. [PubMed: 11244043]

96. Fukata M, Chen A, Klepper A, Krishnareddy S, Vamadevan AS, Thomas LS, Xu R, Inoue H, Arditi M, Dannenberg AJ, Abreu MT. Cox-2 is regulated by Toll-like receptor-4 (TLR4) signaling: Role in proliferation and apoptosis in the intestine. Gastroenterology. 2006; 131:86277. [PubMed: 16952555]

97. Brown SL, Riehl TE, Walker MR, Geske MJ, Doherty JM, Stenson WF, Stappenbeck TS. Myd88dependent positioning of Ptgs2-expressing stromal cells maintains colonic epithelial proliferation during injury. J Clin Invest. 2007; 117:258-69. [PubMed: 17200722] 
98. Kampfer H, Paulukat J, Muhl H, Wetzler C, Pfeilschifter J, Frank S. Lack of interferon-gamma production despite the presence of interleukin-18 during cutaneous wound healing. Mol Med. 2000; 6:1016-27. [PubMed: 11474118]

99. Hu B, Elinav E, Huber S, Booth CJ, Strowig T, Jin C, Eisenbarth SC, Flavell RA. Inflammationinduced tumorigenesis in the colon is regulated by caspase-1 and NLRC4. Proc Natl Acad Sci U S A. 2010; 107:21635-40. [PubMed: 21118981]

100. Allen IC, TeKippe EM, Woodford RM, Uronis JM, Holl EK, Rogers AB, Herfarth HH, Jobin C, Ting JP. The NLRP3 inflammasome functions as a negative regulator of tumorigenesis during colitis-associated cancer. J Exp Med. 2010; 207:1045-56. [PubMed: 20385749]

101. Hirota SA, Ng J, Lueng A, Khajah M, Parhar K, Li Y, Lam V, Potentier MS, Ng K, Bawa M, McCafferty DM, Rioux KP, Ghosh S, Xavier RJ, Colgan SP, Tschopp J, Muruve D, MacDonald JA, Beck PL. NLRP3 inflammasome plays a key role in the regulation of intestinal homeostasis. Inflamm Bowel Dis. 2011; 17:1359-72. [PubMed: 20872834]

102. Bauer C, Duewell P, Mayer C, Lehr HA, Fitzgerald KA, Dauer M, Tschopp J, Endres S, Latz E, Schnurr M. Colitis induced in mice with dextran sulfate sodium (DSS) is mediated by the NLRP3 inflammasome. Gut. 2010; 59:1192-9. [PubMed: 20442201]

103. Rosenberg DW, Giardina C, Tanaka T. Mouse models for the study of colon carcinogenesis. Carcinogenesis. 2009; 30:183-96. [PubMed: 19037092]

104. Dove WF, Clipson L, Gould KA, Luongo C, Marshall DJ, Moser AR, Newton MA, Jacoby RF. Intestinal neoplasia in the ApcMin mouse: independence from the microbial and natural killer (beige locus) status. Cancer Res. 1997; 57:812-4. [PubMed: 9041176]

105. Rakoff-Nahoum S, Medzhitov R. Regulation of spontaneous intestinal tumorigenesis through the adaptor protein MyD88. Science. 2007; 317:124-7. [PubMed: 17615359]

106. Lee SH, Hu LL, Gonzalez-Navajas J, Seo GS, Shen C, Brick J, Herdman S, Varki N, Corr M, Lee J, Raz E. ERK activation drives intestinal tumorigenesis in Apc(min/+) mice. Nat Med. 2010; 16:665-70. [PubMed: 20473309]

107. Coussens LM, Werb Z. Inflammation and cancer. Nature. 2002; 420:860-7. [PubMed: 12490959]

108. Tanaka T, Kohno H, Suzuki R, Yamada Y, Sugie S, Mori H. A novel inflammation-related mouse colon carcinogenesis model induced by azoxymethane and dextran sodium sulfate. Cancer Sci. 2003; 94:965-73. [PubMed: 14611673]

109. Suzuki R, Kohno H, Sugie S, Tanaka T. Sequential observations on the occurrence of preneoplastic and neoplastic lesions in mouse colon treated with azoxymethane and dextran sodium sulfate. Cancer Sci. 2004; 95:721-7. [PubMed: 15471557]

110. Tarmin L, Yin J, Harpaz N, Kozam M, Noordzij J, Antonio LB, Jiang HY, Chan O, Cymes K, Meltzer SJ. Adenomatous polyposis coli gene mutations in ulcerative colitis-associated dysplasias and cancers versus sporadic colon neoplasms. Cancer Res. 1995; 55:2035-8. [PubMed: 7743497]

111. Itzkowitz SH, Yio X. Inflammation and cancer IV. Colorectal cancer in inflammatory bowel disease: the role of inflammation. Am J Physiol Gastrointest Liver Physiol. 2004; 287:G7-17. [PubMed: 15194558]

112. Salcedo R, Worschech A, Cardone M, Jones Y, Gyulai Z, Dai RM, Wang E, Ma W, Haines D, O'HUigin C, Marincola FM, Trinchieri G. MyD88-mediated signaling prevents development of adenocarcinomas of the colon: role of interleukin 18. J Exp Med. 2010; 207:1625-36. [PubMed: 20624890]

113. Zaki MH, Vogel P, Body-Malapel M, Lamkanfi M, Kanneganti TD. IL-18 production downstream of the Nlrp3 inflammasome confers protection against colorectal tumor formation. $\mathrm{J}$ Immunol. 2010; 185:4912-20. [PubMed: 20855874]

114. Hu B, Elinav E, Flavell RA. Inflammasome-mediated suppression of inflammation-induced colorectal cancer progression is mediated by direct regulation of epithelial cell proliferation. Cell Cycle. 2011; 10:1936-9. [PubMed: 21555913]

115. Abdelaziz DH, Gavrilin MA, Akhter A, Caution K, Kotrange S, Khweek AA, Abdulrahman BA, Hassan ZA, El-Sharkawi FZ, Bedi SS, Ladner K, Gonzalez-Mejia ME, Doseff AI, Mostafa M, Kanneganti TD, Guttridge D, Marsh CB, Wewers MD, Amer AO. Asc-dependent and 
independent mechanisms contribute to restriction of legionella pneumophila infection in murine macrophages. Front Microbiol. 2011; 2:18. [PubMed: 21713115] 


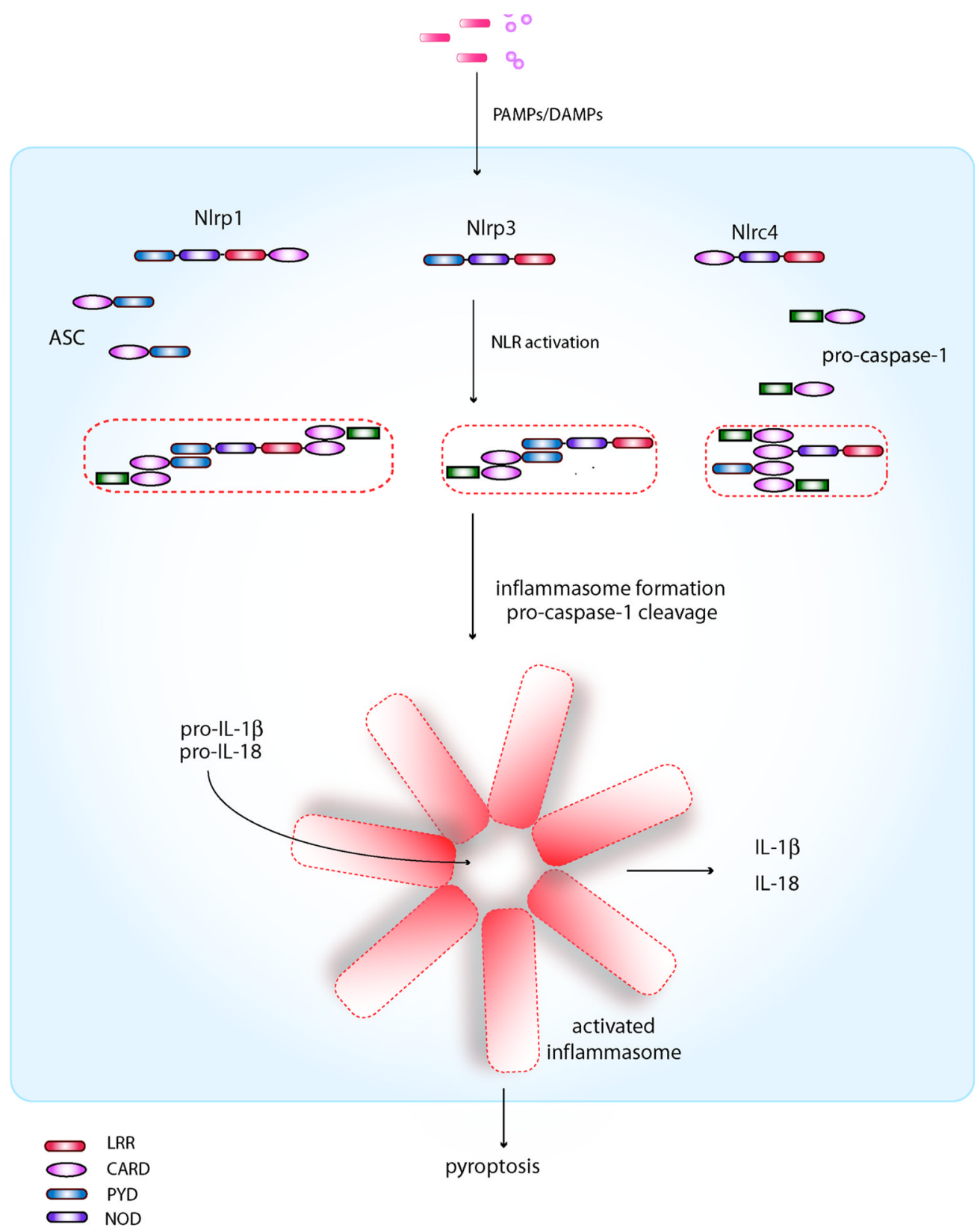

Figure 1. Inflammasome components and assembly

With the exception of Aim2 (not shown), all known inflammasomes consist of an NLR, which contain either a PYD domain or a CARD domain that can physically interact with the PYD or CARD domain of ASC and caspase-1, respectively. Both Nlrp1 and Nlrc4 contain a CARD domain that can directly independently of ASC; however, the addition of ASC in the inflammasome assembly can enhance its activity in the case of Nlrp1. The Nlrp3 inflammasome on the other hand may form different inflammasome complexes depending on the requirement for $\mathrm{ASC}^{115}$. Oligomerization of ASC and the NLR results in a macromolecular complex consisting of multiple subunits that are capable of cleaving procaspase- 1 to its active form, resulting in the cleavage of the pro-forms of IL- $1 \beta$ and IL-18 to their mature, biologically active forms. Activation of caspase- 1 also leads to pyroptosis. 


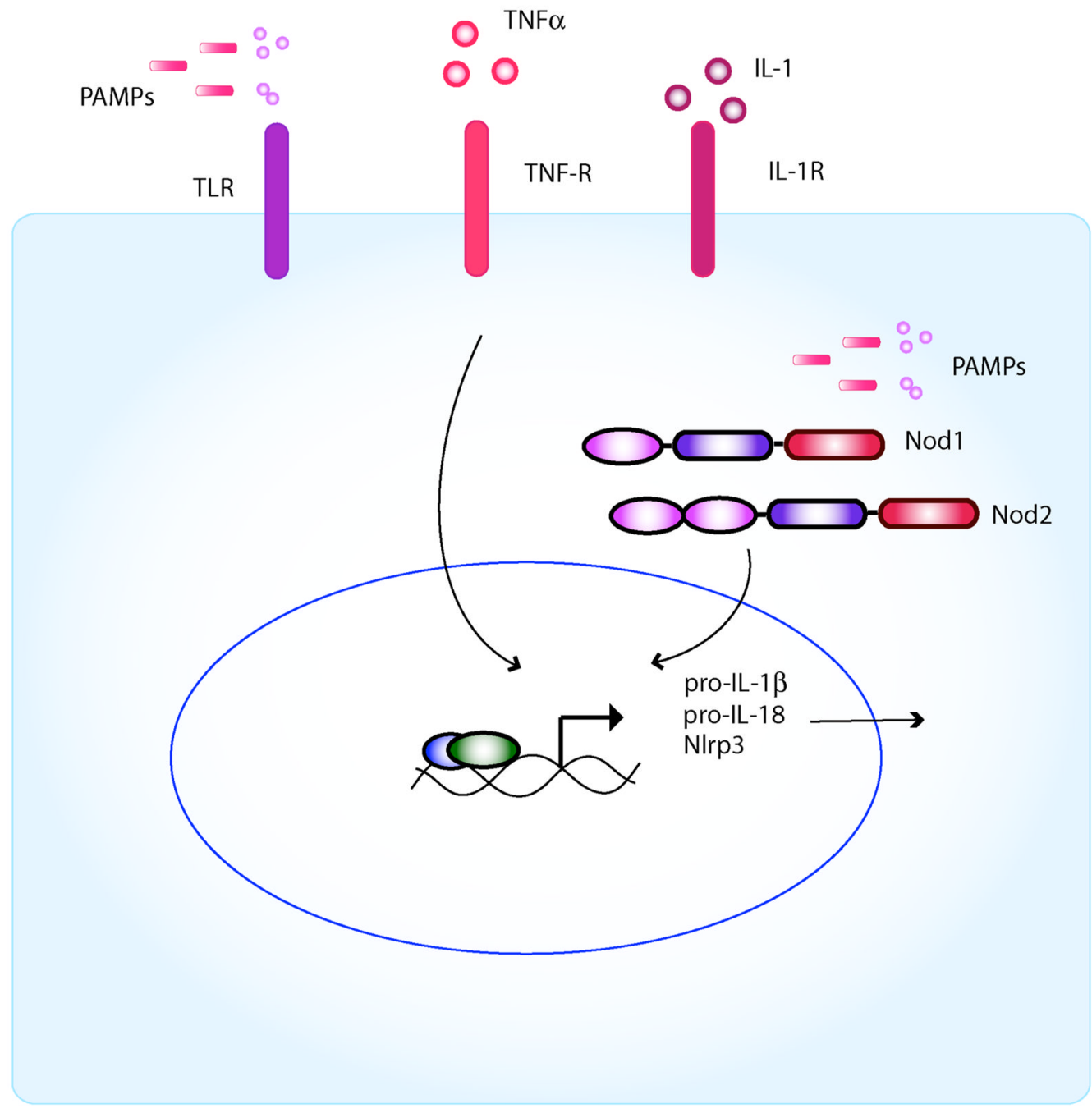

Figure 2. Activation of the NIrp3 inflammasome requires 2 steps

A, Priming step: Based primarily on studies of Nlrp3, inflammasome activity requires first the production of pro-IL-1 $\beta$ and Nlrp3 through upregulation of NFKB by either activation of the TLRs or Nod1/2. Inflammatory cytokines such as TNFa or IL-1 can also induce NFrB. In addition, this first signal (i.e., cytokines, TLR or Nod1/2 activation) also results in the transcriptional upregulation of Nlrp3. B, Activation step: It remains unclear how Nlrp3 is activated by diverse signals. Three different mechanisms have been suggested: 1) Intracellular potassium depletion by the opening of a pore via ATP-dependent P2X7R activation or microbial pore-forming toxins, 2) lysosomal membrane damage and release of activated cathepsin B after endocytosis of sterile particulates such as silica, asbestos and cholesterol crystals, and 3) generation of ROS from the mitochondria as a consequence of cellular injury (although ROS may affect inflammasome priming only). 


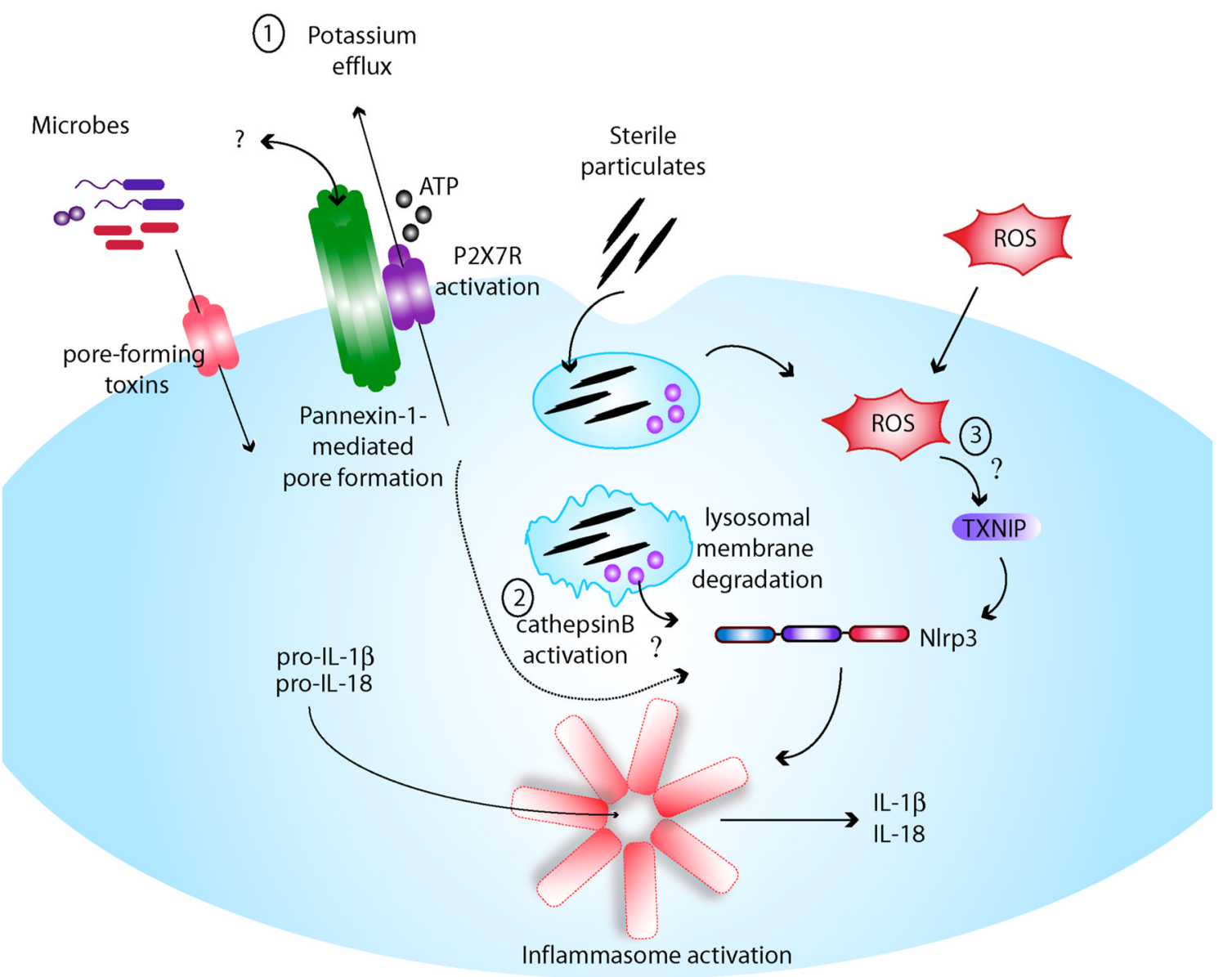

Figure 3. IL-18 is important for intestinal epithelial repair

Nlrp3-, ASC- and caspase-1-deficient mice have increased susceptibility to DSS-induced colitis. DSS causes direct epithelial injury resulting in increased permeability and translocation of bacteria into the breached mucosa leading to an inflammatory response that includes the recruitment of immune cells such as macrophages and neutrophils. The production of IL-18, such as by the Nlrp3-inflammasome, allows the epithelium to be fully restituted, limiting the extent of inflammation. The precise cellular source of IL-18 and how IL-18 promotes epithelial repair (e.g., whether it acts directly on the epithelial cell or indirectly through lamina propria cells) remain unclear. 


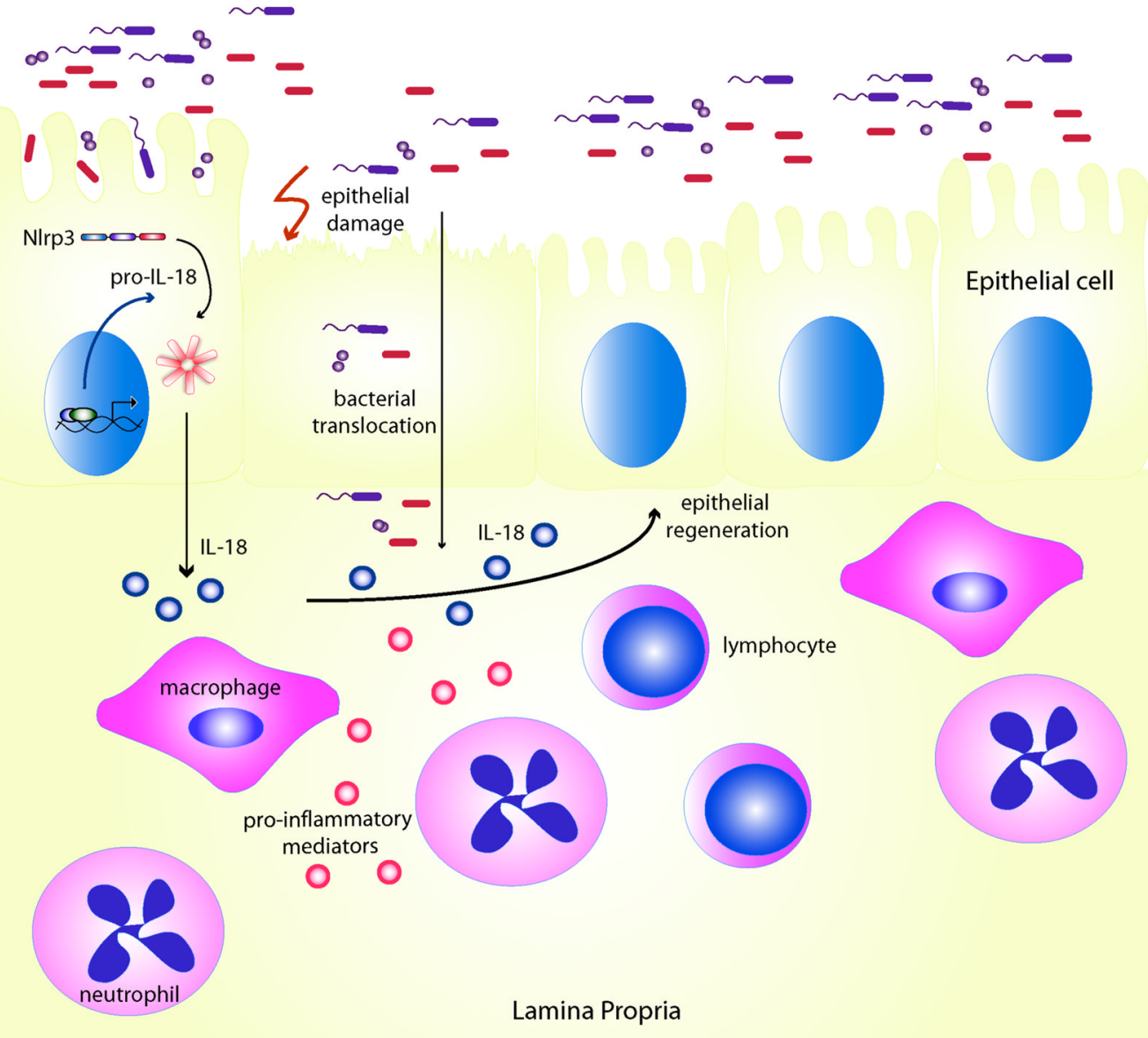

Figure 4. Model of Nlrp6-mediated regulation of intestinal and microbial homeostasis Nlrp6 maintains intestinal homeostasis by regulating the composition of the gut microbiome and the production of IL-18 (left). In the absence of Nlrp6 (right), there is dysbiosis resulting in the accumulation of colitogenic bacteria, upregulation of inflammatory mediators, such as CCL5, and subclinical inflammation. Upon additional epithelial damage by DSS, rampant inflammation ensues as a result of impaired epithelial repair from decreased IL-18 production.. 

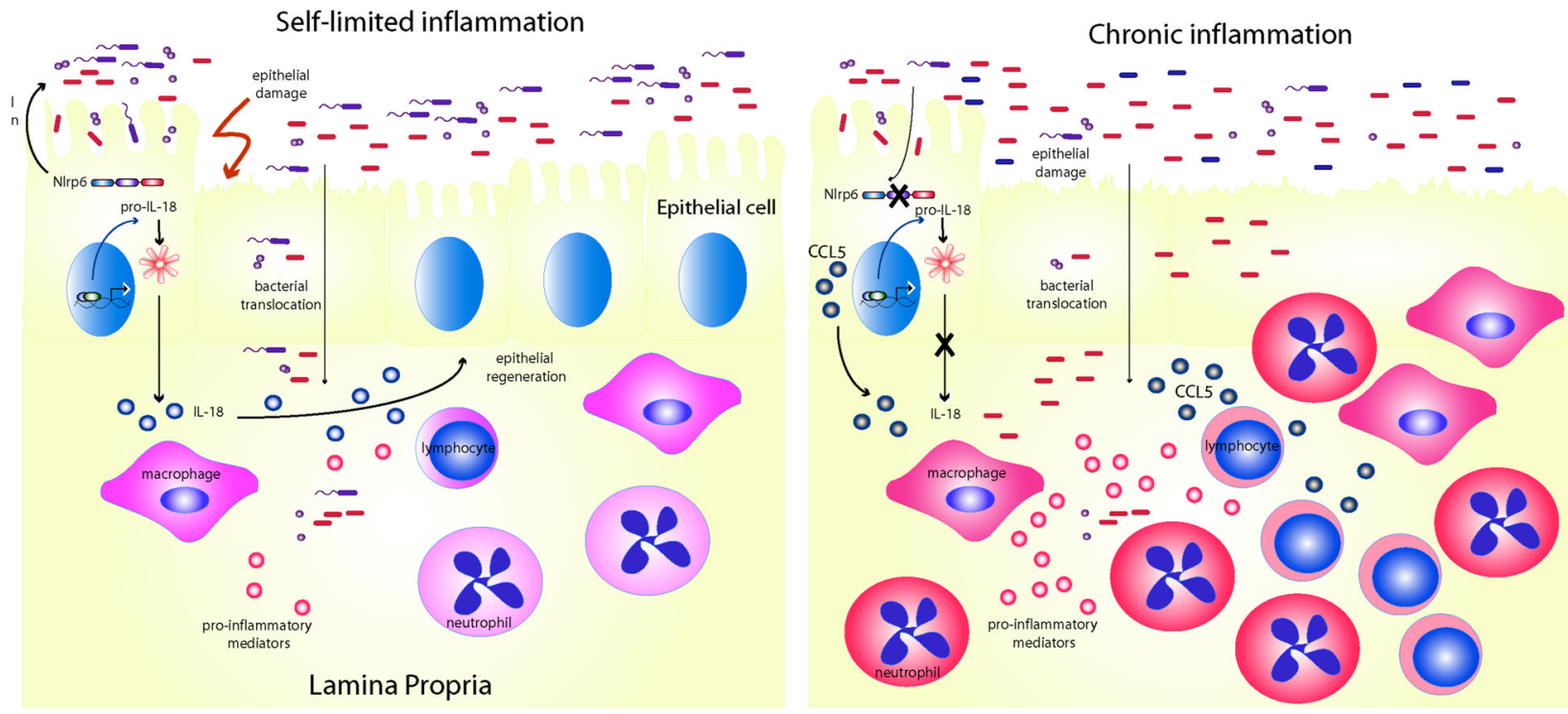

Figure 5. The inflammasome protects against colitis-associated tumorigenesis through multiple mechanisms

Mice deficient in inflammasome activity have increased susceptibility to colitis-associated tumorigenesis. Specifically, Nlrp3, Nlrc4, and Nlrp6 all have been demonstrated to negatively regulate colitis-associated tumorigenesis (see text for details). Bone marrow chimera experiments suggest that Nlrp3 and Nlrp6 mediate tumor suppression within the hematopoietic compartment; however, mouse chimera experiments suggest that a nonhematopoietic compartment (epithelial or stromal cells) is important for Nlrc4-mediated tumor suppression. Although the mechanism still remains unclear, IL-18 may be an important factor in the protection against neoplasia by Nlrp3 and Nlrp6. Unlike Nlrp3 and Nlrp6, the absence of Nlrc4 signaling is not associated with increased inflammation. Instead, Nlrc4 appears to limit tumor development by regulating epithelial proliferation and apoptosis either in the intestinal epithelium or within the tumor itself. 
Table 1

\begin{tabular}{|c|c|c|c|}
\hline Pathogen & Microbial Activator & Inflammasome & References \\
\hline \multicolumn{4}{|l|}{ BACTERIAL } \\
\hline Staphylococcus aureus & Hemolysins & Nlrp3 & Munoz-Planillo et al. 2010 \\
\hline Vibrio cholera & HlyA and MARTX $\mathrm{Vc}_{\mathrm{c}}$ & Nlrp3 & Toma et al. 2010 \\
\hline Streptococcus pyogenes & Streptolysin O & Nlrp3 & Harder et al, 2010 \\
\hline Chlamydia pneumonia & unknown & Nlrp3 & He at. 2010 \\
\hline Neisseria gonorrhea & unknown & Nlrp3 & Duncan et al, 2009 \\
\hline Mycobacterium tuberculosis & unknown & Nlrp3, Nlrc4 & Koo et al. 2008; Master et al. 2008 \\
\hline Listeria monocytogenes & $\begin{array}{l}\text { LLO, flagellin, bacterial } \\
\text { DNA }\end{array}$ & Nlrp3, Nlrc4, Aim2 & $\begin{array}{l}\text { Mariathasan, 2006; Warren et al. 2008; Sauer et al. } \\
\text { 2010; Wu et a. 2010; Tsuchiya K 2010; Meixenberger } \\
\text { K } 2010\end{array}$ \\
\hline Salmonella typhimurium & Flagellin, PrgJ & Nlrc4, Nlrp3 & $\begin{array}{l}\text { Franchi et al. 2006; Miao et al. 2006; Miao et al. 2010 } \\
\text { Broz et al. } 2011\end{array}$ \\
\hline Shigella flexneri & Mxil? & Nlrc4; Nlrp3 & $\begin{array}{l}\text { Susuki et al. 2007; Miao et al.2010; Willingham SB } \\
\text { 2007; }\end{array}$ \\
\hline Pseudomonas aeruginosa & Flagellin & Nlrc4 & Franchi et al.2007; Galle et al, 2007 \\
\hline Legionella pneumophila & Flagellin & & Amer et al.; Lightfield KL 2008; Zamboni DS, 2006 \\
\hline Bacillus anthracis & Lethal toxin & Nlrp1b & Nour et al. 2009, Boyden ED 2006; Terra JK, 2010 \\
\hline Franciscella tularensis & Bacterial DNA & Aim2 & $\begin{array}{l}\text { Fernandes-Alnemri et al. 2010; Rathinam et a. 2010; } \\
\text { Jones et al. } 2010\end{array}$ \\
\hline \multicolumn{4}{|l|}{ FUNGAL } \\
\hline Candida albicans & unknown & Nlrp3 & Gross et al. 2009; Hise et al, Joly S 2009 \\
\hline Aspergillus fumigatus & unknown & Nlrp3 & Said-Sadier et al. 2009 \\
\hline \multicolumn{4}{|l|}{ VIRAL } \\
\hline Sendai virus & unknown & Nlrp3 & Kanneganti et al. 2006 \\
\hline Influenza A & Viral M2, viral RNA? & Nlrp3 & $\begin{array}{l}\text { Thomas et al. 2009; Allen et al. 2009; Ichinohe et al. } \\
2009\end{array}$ \\
\hline Adenovirus & unknown & Nlrp3 & Muruve et al. 2008 \\
\hline Varicella-zoster & unknown & Nlrp3 & Nour et al. 2011 \\
\hline Cytomegalovirus & viral dsDNA & Aim2 & Rathinam et al. 2010; \\
\hline Vaccinia virus & viral dsDNA & Aim2 & Hornung et al. 2009; Rathinam et al. 2010 \\
\hline
\end{tabular}

